\title{
Endopleurale Operationen unter der Leitung des Thorakoskops.
}

\author{
Von \\ H. C. Jacobaeus.
}

Mit 18 Figuren auf 10 Tafeln und 1 Textfigur.

Vor dem medizinischen Kongress in London August 1913 erwähnte ich in einem Vortrag über die praktische Anwendbarkeit der Laporo-Thorakoskopie ${ }^{1}$ ), dass es mir kurz zuvor gelungen war, die erste kleine Operation in der Pleurahöhle unter der Leitung des Thorakoskops auszuführen. Zusammen mit Herrn Dr. Gullbring hatte ich im Krankenhause St. Göran in einem Fall von Lungentuberkulose, behandelt mit Pneumothorax, versucht, durch einen dünn€n Trokar in ein benachbartes Interstitium einen Galvanokauter einzuführen und vorhandene Verwachsungen zwischen Lunge und Brustwand abzubrennen. Dies gelang nur zum Teil, da die Verwachsung zu ausgebreitet war. Durch diesen Versuch wurde es mir aber klar, dass die Methode möglich war. Später habe ich gemeinsam mit Herrn Dr. Tideströ $\mathrm{m}^{2}$ ) zwei weitere Fälle beschrieben; in dem einen von diesen gewannen wir ein besonders glänzendes Resultat durch eine derartige Abbrennung.

Aus Anlass dieser Publikation berichtete M. J a cobsson ${ }^{3}$ ) über einen Fall, wo er unter Leitung der Röntgendurchleuchtung eine derartige Abbrennung mit Hilfe eines dünnen, durch einen Trokar eingeführten Galvanokauters versucht hatte. Der Versuch gelang indessen nicht.

i) Über Laporo- und Thorakoskopie. Bra uers Beiträge. Bd. XXV. H. 2.

2) Hygiea 1914. H. 15 .

3) Hygiea 1914. H. 16.

Beiträge zar Klinik der Tuberkalose. Bd. XXXV. H. 1. 
Zuvor hatte Hervé1) Februar 1914 ähnliche Vorsuche in nicht weniger als drei Fällen publiziert: die Technik war twas abweichend von derjenigen $J$ a cobssons, indem Herrésich teils der Röntgendurchleuchtung zur Orientierung in dor Brusthöhle, teils aussordem eines ,stylet explorateur" bedient hatte, mitte's dessen er die Adhïrenz auffing, um sie dann mit cinem Galvanokauter abzubrennen. In zwei von diesen Fällen wurde die Operation in 5--6 Sitzungen ausgeführt mit sichtlicher Bcsserung in beiden Fällen. Die cinzige Komplikation war ein leichtes Hautemphysem. Lim dasselbe zu vermeiden, musste man den intrapleuralen Druck nach der Operation auf Nul! herabsetzen.

Gegenwärtig ist dies, meines Wissens, alles, was von endopleuralen, nur durch eine oder zwei Punktionsöffnungen an der Thoraxwand ausgeführten Operationen bekannt ist. Dass es einen beachtenswerten Fortschritt in der Pneumothoraxtherapie bedeuten würde, wenn man eine derartige Operationsmethode ausbilden künnte, ist ohne weiteres einleuchtend. Wegen der schädlichen Einwirkungen der Adhärenzen verweise ich auf die in meinem zusammen mit Tideström publizierten Aufsatz nach Sa g man zitierten Äusserungen.

Durch diese Operation würde man in gewissen Füllen jene blutigen und entstellenden Rippenresektionen mit vollständigem oder partiellemi Finsinken der Brustwand rermeiden kömnon. Ferner muss eine Operationsmethode, die in der geschlossenen Pleurahöhle ausgefuhrt wird, unter Termeidung der doch nicht so geringen Nachteile der Ober- und Unterdruckapparate rom chirurgischen Standpunkt aus von sehr grossem Interesse sein. Dies bezcichnet eine chirurgische Betätigung, die vor der Entstehung der Thorakoskopie vollständig unbekannt war.

Lis ist einlouchtond, dass, wenn man auf einem Gebict wio dum vorliegenden eine $n$ ue Methode auszuarbeiten sucht, man behutsam vorgehen muss, um nicht duich Missgriffe die Aussichten auf weitere Fortschritte zunichte zu machen. Hieraus folgt teils, dass die bisher gewonnenon Resultate vollüfig becheiden sein müssen, teils auch dass cin Bericht übor dic Schwierigheiten ron ebenso grossen Wert ist wie eine Mittcilung der vereinzalten günstiren Resulate.

In dem vorliegenden isufsatz werde ich zuest in allor hürze über die zuror publizierten Fäle und dam ausführlicher aber drei neue Fälle berichten, in welchen ich die Methode versucht habe, in allen gemeinsam mit Dr. Tideström. Ausserdem habe ich in

1) Journal d. Praticiens. 14. Febr. 1914. 
diesen Fällen wie auch in einigen Sektionsfällen zu ermitteln versucht, inwiefern durch röntgenologische Untersuchung zuverlässige und vollständige Aufklärungen zu gewinnen sind, auf welche die Indikationen der Operation sich stützen können.

In den von mir operierten Fällen habe ich daher das Röntgenresultat mit der Thorakoskopie, in den Sektionsfällen mit dem Sektionsbefund verglichen. In diesen letzteren Füllen habe ich ferner mikroskopische Untersuchungen über den Bau der strangförmigen Adhärenzen gemacht, um zu sehen, ob sich hieraus irgend was von Interesse für die Operationsmöglichkeiten ergeben könnte. Schliesslich habe ich einen Vergleich zwischen meinem, Hervés und Jacobssons Verfahren für den endopleuralen Eingriff angestellt.

Bei der Röntgenuntersuchung sieht man meistens diese strangförmigen Adhärenzen ausserordentlich deutlich und schön hervortreten. Für eine Operationsdiagnose ist dies jedoch nicht ausreichend, wie aus dem Folgenden hervorgeht, denn häufig ist es unmöglich, durch Röntgen die Dimensionen der Adhärenzen zu bestimmen, z. B. ob eine horizontal gelegene Adhärenz einem Faden oder einer Membran entspricht. Man muss sich ferner darüber informieren, ob die Adhärenzen in der Pleurahöhle eine derartige Lage haben, dass es möglich ist, sie mit dem Galvanokauter zu erreichen, und an welcher Stelle man am zweckmässigsten den Galvanokauter einführen soll, damit die Ausführung der Operation möglich sei. Meine zwar sehr bescheidene Erfahrung geht in der Richtung, dass sowohl die Orientierung bei der Thorakoskopie als auch das Manövricren des Galvanokauters meistens schwieriger ist, als wie man auf Grund der Röntgenuntersuchung erwarten sollte. Bei den Operationen, die ich hier beschreibe, werde ich deshalb besonders bei der Übereinstimmung zwischen der Röntgenuntersuchung und der Thorakoskopie verweilen.

Von den gemeinsam mit Ti deström beobachteten Fällen will ich nur ganz kurz den 1. und 2. erwähnen. In beiden Fällen wurden so grosse Verwachsungen gefunden, dass es nicht möglich war, einell Vergleich zwischen der Röntgenuntersuchung und der Thorakoskopie anzustellen. In beiden Fällen handelte es sich um Versuchsoperationen, wo es im voraus einleuchtend war, dass man die Adhärenzen nicht vollständig würde lösen kömnen.

Fall 3. F. B., Krankenpflegerin, 22 Jahre. Lungentuberkulose wurde Oktober 1913 diagnostiziert. Aufgenommen im Sanatorium Sülsjö am 29. XI. 1913.

Lungenbefund: C̈ber der ganzen 1. Lunge mittelstarke Dämpiung, schwache, unreine Resp. und spürliches Rasseln. Über der r. Spitze leichte Dämpfung, rauhe Resp, und vereinzeltes Rasseln, ausserdem hie und da sowohl 
vorne wie hinten einzelne Rasselgeräusche. Im A uswurf + Tb. (Massen). Te mp. 37,20-380. Laryngit is (The.?), Herz, Puls, Harn o. B.

Ein künstlicher Pneumothorax wurde am 29. XII. angelegt (Stickstoff). Nach der 4. Insufflation waren die Rasselgeräusche über der l. Lunge verschwunden und die Resp. aufgehoben; an der r. Lunge waren nur vorne-lateral im III.-IV. Interstit. einzelne Rasselgeräusche zu hören; im übrigen die r. Lunge frei von Rasselgeräuschen.

Der Lungenbefund hat sich dann unverändert gehalten. Ende Ianuar trat ein unbedeutendes Exsudat auf, das nach 1 Woche resorbiert war. In Auswurf die ganze Zeit hindurch + Th., zahlreich (zweimal im Monat untersucht). Die Temp. die ganze Zeit hindurch febril his Anfang April, wo sie herunterging und afebril wurde, so dass Pal. das Pent verlassen durfte. Sie hatte jetzt 20 Insufflationen, variierend zwischen 200 und $500 \mathrm{ccm}$, erhaiten (ausgenommen die ersten Male, wo nur $80-150 \mathrm{ccm}$ insuffliert wurden).

Die Röntgenaufnahme zeigte eine Kaverne, die durch eine Adhïrenz obenlateral (Fig. 1) ausgespannt gehalten wurde; diese hatte nicht zum Bersten gebracht werden können, weder durch hohen Druck (dic Pat. vertrug keinen höheren Druck als $+12-1+4 \mathrm{~cm} \mathrm{H}_{2} \mathrm{O}$ ) noch durch häufige Insufflation ron kleinen Gasmengen.

Am 21. V. 1914. Operation. Bei der Thorakoskopie sieht man die Lunge am Hilus komprimiert liegend. Die Pleura verdickt, grauweiss, glänzend. Am Mittellappen sind einige ziemlich grosse Knoten, die Lungenoberfläche vorwölbend, zu sehen. Nach dem Zwerchfell hin sah man eine s. g. Calsche Adhärenz, welche breit, dick und weissglänzend von der unteren Lungenoberfläche nach der Zwerchfellkuppel verläuft.

Vom oberen Teil der Lunge, jedoch nicht ron der Spitze, geht ein kaum kleinfingerdicker Strang in der Richtung nach oben, aussen und hinten aus, der allmählich schmäler wird und sich an der Thoraxwand befestigt (Fig. 1). Der Einstich für das Thorakoskop wurde im 4. Interstitium gemacht. Ein Interstitium weiter oben, etwa in der vorderen Axillarlinie, wurde der Trokar eingeführt.

Durch diesen letzteren hindurch wurde der Abbrenner eingeführt, und nachdem ich mich während ein paar Minuten orientiert hatte, gelang es mir, den Abbrenner nahe der Befestigung der Adhärenz an der Pleura parietalis zu plazieren. Dann ging die Abbrennung in einem Bruchteil einer Minute vonstatten, und auf Grund der Lage des Pat. sank die Lunge herunter, mit der Adhärenz eine S-förmige Krümmung bildend. Bei der Abbrennung sclbst kam ich aus Versehen der Pleura zu nahe, weshalb die Pat. einen ganz unbedeutenden momentanen Schmerz empfand. Nachher wurde eine Röntgenaufnahme gemacht, die das Resultat der Abbrennung zeigte, worauf die Pat. selbst in ihr Zimmer hinunter spazierte (Fig. 2).

Während der ersten 6 Tage nach der Operation stieg die Temp., so dass sie $37,4^{0}-38^{\circ}$ war, fiel dann aber rasch bis zur Norm, 36, $2^{0}-37.3^{\circ}$. Keine subjektiven Beschwerden. Am 23. V. wurde eine neue Insufflation von $300 \mathrm{ccm}$ gemacht; der Druck hierbei $+7-+1$. Im Auswurf konnten am 2. VI. keine Tb. nachgewiesen werden (zahlreiche Direkt- und Antiforminpräparate). Bei Untersuchung des Auswurfs am 13. VI. nach Insufflation den Tag vorher konnten nach Absuchen mehrerer Präparate einzelne $\mathrm{Tb}$. nachgewiesen werden (wie zuvor erwähnt, fanden sich vor der. Operation stets zahlreiche Tb.). Die Pat. ist nunmehr in ihrer Heimat und soll die Behandlung ambulatorisch fortsetzen. 
Am 1. VII. erneute Lntersuchung: der Zustand nach wie vor gut. Dieses Mal konnte die Pat. keinen Auswurf mitbringen, da dieser völlig aufgehört hatte. Die Röntgenuntersuchung zeigte vollständigen Kollaps der Lunge. Die Kaverne ist gleichfalls komprimiert (Fig. 3).

Der Zustand ist den ganzen Winter hindurch befriedigend gewesen. Im April ,erkältete sich" die Pat., worauf der begrenzte Prozess in der r. Lunge sich etwas auszubreiten schien, weshalb die Prognose gegenwärtig zweifelhaft ist.

Die neuen Fälle, in welchen ich die Methode versucht habe, sind:

Fall 4. K. S., Stud. phil., 24 Jahre. Lungentuberkulose wurde August 1913 kunstatiert. Aufgenommen im Sanatorium Säfsjö am 6. XI. 1913.

St. pr. bei der Aufnahme: Mittelstarke Dämpfung, scluwache, unreine Resp. über der oberen Hälfte beider Lungen; vereinzelte Rasselgeräusche über dem oberen Teil der 1. Lunge. Die Röntgenaufnahme zeigte eine gelinde, diffuse Marmorierung der ganzen 1 . Lunge sowie einzelne kleine Herde hie und da in der $r$. Lunge. A uswurf: zahlreiche Tb. Temp.: afebril. Auf Grund wiederholter Hämoptysen wurde Pneumothorax (linke Seite) am 22. XII. 1913 angelegt. Nach der 7. Insufflation, 20. I. 1914, war die Lunge komprimiert; es fand sich aber eine mässig. dicke Adhärenz lateral in der Mitte. Cleichzeitig wurde ein kleines Exsudat konstatiert. Das Exsudat bestand die ganze Zeit fort, während der Pat. im Sanatorium gepflegt wurde; es war die ganze Zeit über von ziemlich geringem Umfang, serös. Es wurde zweimal entleert, das erste: Mal $75 \mathrm{ccm}$, das zweite Mal $300 \mathrm{ccm}$. Am 9. VII. 1914 hatte der Pat. 16 Insufflationen erhalten, von höchstens $1000 \mathrm{ccm}$ mit einem Druck von $+6-+7 \mathrm{~cm}$ (paradoxale Oszillationen), aber die Adhärenz konnte doch nicht zum Reissen gebracht werden. Die Zahl der Bazillen hatte während der Behandlung kontinuierlich abgenommen ( 2 Proben im Monat), und seit Anfang Juni war der Auswurf bazillenfrei. Die r. Lunge die ganze Zeit hindurch frei von Rasseln.

Am 17. VII. 191 wurde der Pat. in das Seraphimerlazarett aufgenommen zwecks Abbrennung der in Rede stehenden Adhärenz. Operation am 18. VII. Das Thorakoskop wurde nach Anästhesierung vorne im VI. Interstitium eingeführt, der Galvanokauter in dem nächst höheren Interstitium. Die Anästhesie gut gelungen. Ohne Schwierigkeit konnte ich den Galvanokauter gegen die Adhärenz richten. Ich versuchte abzubrennen, wo die Adhärenz ziemlich schmal war, jedoch der Lunge nüher als der Pleura parietalis. Bei der ersten Berührung entstand eine unbedeutende kapilläre Blutung. Ich versuchte dieselbe zu stillen, indem ich den Galvanokauter in unmittelbarer Nähe dør blutenden Stelle hielt. Da dies nicht gelang, brach ich die Operation ab. Der Pat., der keinerlei Beschwerden von der Operation hatte, wurde 2 Tage nachher, am 20. VII. 1914, entlassen, um nach einiger Zeit wiederzukommen. Seitdem hat er indessen nichts mehr von sich hören lassen. (In einem Brief an Dr. Tideström rom 27. X. 1914 hat er mitgeteilt, er sei relativ arbeitsfähig, afebril, das Sputum nach wie vor bazillenfrei, es findet sich noch immer ein Exsudat, hat $1,5 \mathrm{~kg}$ an Gewicht zugenommen, nunmehr niemals Bluthusten usw.)

Epikrise: Zu der Krankengeschichte ist nicht viel hinzuzufügen. Es besteht gute Übereinstimmung zwischen Röntgen und Thorakoskopie. Nur zeigt sich bei der Thorakoskopie die Adhärenz 
etwas dicker, als man erwartet hatte. Beim ersten Versuch zum Abbrennen, der zweifelsohne etwas zu nahe der Lunge gemacht wurde, entstand eine unbedeutende Blutung. Da dies eine ganz neue Komplikation darstellte, deren Bedeutung ich nicht abzuschätzen wusste, brach ich die Operation ab. Der Pat. hatte keinerlei Unannehmlichkeiten von derselben. Ein Missgriff war es vielleicht, dass ich die Abbrennung zu nahe der Lunge versuchte.

Die mikroskopischen Untersuchungen, über welche ich im folgenden berichten werde, sprechen dafür, dass die Abbrennung so nahe der Pleura parietalis wie möglich gemacht werden muss. Die Blutung in dem soeben besprochenen Fall war doch so unbedeutend, dass sie mich nicht davon hätte abschrecken sollen, die Operation in grösserer Nähe der Pleura parietalis fortzusctzen. Den Grund zur Entstehung derselben ist mir niemals gelungen zu ermitteln. Sonst entstehen Blutungen am leichtesten, wenn man einen zu stark glühenden Galvanokauter verwendet. $O b$ dies hier der Fall gewesen ist, rermag ich nicht zu entscheiden.

Fall 5. Greta F., unverheiratet, 20 Jahre. Aufgenommen in das Sanatorium säfsjö am 26. III. 1914 (zwecks Observation). War unter Symptomen einer akuten Pneumonie erkrankt. Lungentuberkulose wurde am 29. IV. konstatiert (Bazillen im Auswurf).

Stat. pr. bei der Aufnahme: Mittelstarke Dämpfung über der oberen Hälfte der r. Lunge, kaum hörbare Resp. und Rasseln in mässiger Menge. Lie l. Lunge frei von Rasseln. Temp. subfebril. Pneumothorax wurde am 30. II. 191t angelegt. Nach 3 Insufflationen war an der $r$. Lunge kein Rasseln zu hören. Xach der 7. Insufflation zeigte die Röntgenuntersuchung einen mittelgrossen, lateralen Pneumothorax. Die äusseren Konturen der Lunge nach oben hin deutlich. Entsprechend dem 1I. Interstitium eine schmale strangförmige Adhärenz, die etwa $1 \mathrm{~cm}$ breit an der Lunge anfängt, sich aber dann in 2 stränge teilt, rie sich voneinander getrennt an der Brustwand etwa im II. Inlerstitium befestigen (Fig. 4). Die Adhärenz scheint keine nennenswerte Traktion auf die Lunge auszuüben. Im III. Interstitium wird die Lungengrenze mehr diffus, mit doppeiter Kontur: eine kräftigere, die auf den Hilus zu abbiegt, und eine äussere, die wie ein Schleier mit einer breiten Spitze nach aussen zieht. Vgl. Fig. 5. Der Unterlappen ist nur partiell komprimiert und, wie es scheint, immer noch etwas luftführend. Dem III. Interstitium an der Vorderseite entsprechend sicht man eine $3 \times 3 \mathrm{~cm}$ grosse Kaverne. Die vorerwähnten schmalen Adhärenzen scheinen gerade ror derselben auszugehen. Die Lunge ist doch nicht dermassen in eine Spitze ausgezogen, wie im vorhergehenden Fall, sondern scheint die Konturierung des Oberlappens durch andere Lrsachen bedingt zu sein. Bei schräger Durchleuchtung sieht man den Oberlappen ganz nahe der rorderen Brustwand liegend. Am 28. VIII. hatte die Pat. 14 Insufflationen erhalten, ron höchstens $800 \mathrm{ccm}$, mit einem Maxinaldruck von $+8-+\downarrow \mathrm{cm}$. Der A uswurf die ganze Zeit hindurch bazillenhaltig. Die Temp. wurde völlig afebril etwa nach einem Monat rom Beginn der Behandlung ab.

Operation am 18. IX. Nach lokaler Anästhesie, die jedoch nicht vollsıanlig wirde (wahrscheinlich zu alte Novokainlösung), wurde das Thorakoskop 
im 1. Interstitiun eingestochen. Bei der Thorakoskopie waren oben und vurne breite Verwachsungen mit schmalen Ausläufern nach unten hin zu sehen. An der Lunge befestigen sich die Adhärenzen an den unteren Teil des Oberlappens. ein Streifen kommt von der oberen Wand der Inzisur. Der Trokar für den Abbrenner wiurfe im IV. Interstitium nach oben vom Thorakoskop eingeführt.

1)ie heralzielıenden tdhärenzen an der vorderen Thoruxwand wurden so nahe der Pleura parietalis wie möglich abgebrannt. Eine in der Frontalebene verlaufende Adhärenz gelang mir nicht abzubrennen. Wenigstens drei dorartige Verwachsungen wurlen abgebrannt, auch die dazwischenliegenden Verhindungen derselben wurden beseitigt, jedoch ohne dass man die ganze Breite der Adhürenz durchsetzen konnte. Die Operation war auch recht schmerzhift uml durch einen unglücklichen Zufall wurde sie ausserdem verlüngert auf Grund vorühergehender Versagens des elektrischen Stromes. Zum grossen Teil rührte dies ron der weniger gut gelungenen Anästhesie her. Jede kleine Bewegung des Thorakoskops verursachte heltige Schmerzen. Die Brennung schien keinen sichmerz herrorzurufen. obgleich sie hart an der Thoraxwand ausgeführt wurde. ler Interlappen war hell und etwas luftführend und machte deutlich kleinere tembewegungen. Keine Blutung in die Pleura. Nach der Operation war die Pat. recht schwach und hatte nachmittags zwei Ohnmachtsanfälle. Wehrere Nale vorber war sie nich den Finhlasungen ohmmïchtig geworden.)

Eine Röntgenuntersuchung unmitteliar nach der Operation zeigte anähernd rieselben rerhältnisse Fis. (6). Nur di: untere Begrenzung des Oberlappens crschien schärfer und laterid in einen Zapfen abslaufend. Die oberen strangförmigen Jdhärenzen sind nicht verändert. Jie Kaverne misst $0.5 \mathrm{~cm}$ weniger in Durchmesser als rother.

Alsdinn sind des weiteren 10 Insuftationen gemacht worden, variicrend zwischen 200 und $1000 \mathrm{ccm}$ bei einem l)ruck ron höchstens $\frac{1}{1} 8-\frac{1}{1}+\mathrm{cm}$.

füntgenuntersuchung am 13. X. bie lange ist ersichtlich siärker kollabiert als zuvor. Wie obren Whiirenzen noch mehr gedehnt, üben aler kwinen rennens. werten Zug auf die Kavernenwand ans. Der untere Teil des ob rlupens endigt in einem scharfen Dreieck. desse.t Spitze einer Albärenz nicht wnihnlich ist. Die Kaverne ersichtlich kleiner, misst kaum $2 \times 2 \mathrm{~cm}$.

Röntgenuntersuchung am 28. XII. (Fig. 7). Die Lunge noch stirtier kollabiert. Die schmalen Adhärenzen nach oben hin sind immer noch stark gestreckt, aber ohne nennenswerte Finwirkung auf die Lungenkontur. Der untere Teil des oherlappens hat scharfe Lmisse, ist etwas spitz ausgezogen, jedoch ohne dass eine Adhärenz go sehen ist. Von der Kaverne ist nur ein schwacher heller Schein etwa $1 \mathrm{~cm}$ breit, $1,5 \mathrm{~cm}$ lang mit recht diffusen Grenzen zu sehen. Die Temp. fortdauemel afebril. Im A us w u f nach wie vor Tb. Las Allgemeinbefinden vorzüglich. Hat niemals ein Exsudat gehabt.

Bei erneuter Röntgenuntersuchang an 30. Januar war die Lunge rollvändig komprimiert. Ther Auswure hatte völlig aufgehört und der Mllgemeinzustand hatte sich des weiteren gebessert.

Der Zustand ist dauernd rorzinglich. Die r. Lunge ist roliständig komprimient. Pat. ist seit Jamnar 1915 bazillenfrei und ohne Fieber.

E pikrisc: Jieser Fall ist in mehreren Beziehungen von Interesse. Bei der Röntgenuntersuchung fand man Veränderungen, die besonders geeignet erschienen für einen Versuch, die strangförmigen Adhärenzen zu beseitigen, welche auf den ersten Anblick die vor- 
handene Kaverne am Zusammenfallen $z u$ hindern schienen. Die Adhärenzen waren so fadendünn, dass man aus triftigen Gründen einen Ausläufer der Kaverne in dieselben hinaus für sehr unwahrscheinlich halten konnte. Von den zwei nächstvorhergehenden Fällen unterscheidet sich dieser Fall dadurch, dass" die äussere Kontur der Lunge gerade vor der Adhärenz nicht in einen Zapfen ausgezogen war. Es hatte den Anschein, als ob die Adhärenz mehr ein Anhängsel sei, ohne nennenswerten Zug auf die Lunge auszuüben, da keine Veränderung an dem Umriss derselben nachzuweisen war. Es bestand einwandfreie Indikation für den Versuch einer Abbrennung, und allem Anschein nach musste der Eingriff leicht vonstatten gehen. Bei der Thorakoskopie konnte man indessen die Verhältnisse, wie man sie sich nach der Röntgenuntersuchung vorgestellt hatte, gar nicht wiedererkennen. Die Lunge lag an der vorderen Brustwand fixiert mit breiten Verwachsungen, die sich mit mehreren Kämmen nach unten fortsetzten. Es war von vornherein einleuchtend, dass es nicht möglich sein. würde, die Verwachsungen vollständig abzubrennen. Auch waren die technischen Schwierigkeiten erheblich, weil die Verwachsung ihren Sitz nach vorne zu hatte. So viel wie möglich wurde abgebrannt, aber nach dem Eingriff konnte man auf den ersten Blick keine Veränderung wahrnehmen. Bei genauerem Studium war es einleuchtend, dass eine kleinere Strecke der unteren Begrenzung des Oborlappens bedeutend schärfere Umrisse zeigte als zuvor. Ich bin geneigt, dies so zu erklären, dass der auf der ersten Aufnahme sichtbare Schleier eine breite an der vorderen Brustwand befestigte Adhärenz gewesen ist, und dass es gerade die unteren Teile der hier gelegenen Adhärenz waren, welche abgebrannt wurden.

Der weitere Verlauf scheint in gewissem Grade diese Erklärung zu stützen, und es ist auch in hohem Grade wahrscheinlich, dass die Abbrennung wirklich von Nutzen gewesen ist, indem die unteren Teile des Oberlappens besser komprimiert werden konnten. Dem pflichtet auch der behandelnde Arzt, Dr. Tideström, bei, der die Pat. weiter beobachtet hat.

Es liegt in der Natur der Sache, dass eine so rasche Besserung wie im Fall 3 unter solchen Verhältnissen nicht zu erwarten war.

Nach und nach ist doch die Kaverne nahezu vollständig komprimiert worden, wie aus der letzten Röntgenaufnahme sowie aus dem Verschwinden der Tuberkelbazillen aus dem Auswurf hervorgeht. Ihr allgemeines Befinden ist, wie aus dem Journal erhellt, vorzüglich. 
Fall 6. T. G., Bäcker, 21 Jahre. Pleurit. sicc. sin. zu wiederholten Malen während der letzten 3 Jahre. Lungentuberkulose wurde April 1914 diagnostiziert. Eine kleinere Nierenblutung Anfang Juni 1914. Aufgenommen in das Sanatorium Säfsjö am 19. X. 1914. Stat. praes.: L. Lunge: Überall sowohl vorne wie hinten starke Lämpfung, schwache Resp., im oberen Teil bronchial. L̈berall zahlreiche Rasselgerüusche, untermischt mit Reibegeräuschen. R. Lunge: Etwas rauhe Resp. und inkonstante Rh. sibil. an der Spitze. Cor o. B. Auswurf: + zahlr. Th. Harn: o. B.

Künstlicher Pneumothorax wurde an 22. X. $191 \pm$ angelegt. Bis zum 30. I. 1915 hatte er 12 Insufflationen ron höchstens $500 \mathrm{ccm}$ unter einem Maximaldruck ron $+14-+12 \mathrm{~cm} \mathrm{H}_{2} \mathrm{O}$ erhalten. Während der Zeit vom 8 . XII. bis 23. XII. $191 \pm$ hatte er ein unbedeatendes Exsudat im Sin. phren. cost. (Röntgen). Bereits nach der 3. Insufflation war die Atmung iiber rer unteren Hälfte der 1. Lunge aufgehoben, aber über der oberen Hälfte waren immer noch Bronchialatmen und zahlreiche Rasselgeräusche zu hören. R. Lunge: Keine Rassel- oder Reibegeräusche. Der Lungenbefund hielt sich alsdann unverändert. Jic Röntgenaufnahme zeigte anfänglich zahlreiche Adhärenzen, von welchen einige nach und nach zum Reissen gebracht wurden, aber die letzten 6 Wochen vor der Operation hielt sich der Röntgenbefund unverändert (Fig. 7). Die Lunge war in das obere Drittel der Pleurahöhle linaufgepresst; von der unteren Oberfläche derselben verlief eine breite Adhärenz nach vorn aussen (bei schrägem Strahlendurchgang zu sehen); ebenfalls ron der unteren Oberfläche erstreckte sich eine schmälere Adhärenz gerade nach unten nach dem Zwerchfell, das in eine Spitze heraufgezogen war. Auch schien das Zwerchfell auf dieser Seite etwas höher zu stehen als auf der anderen.

Operation am 31. I. 1915. Anästhesie mit Novokain. Die Einführung der beiden Trokare ging völlig schmerzfrei vonstatten, ebenso das Manöverieren des Galvanokauters, der in mehreren verschiedenen Richtungen geführt wurde.

Das Thorakoskop wurde durch seinen Trokar im VI. Interstitium etwas nach vorn von der vorderen Axillarlinie eingeführt. Bei den Orientierungs. versuchen schien die Lunge ziemlich komprimiert oben in der Pleurahöhle $z u$ liegen. Von derselben verlief eine breite membranartige ddhärenz nach vorn aussen ganz nahe der Brustwand. Vom medialen Rande derselien setzt sich eine breite handförmige Adhärenz gerade nach unten fort und befestigt sich an das Zwerchfell, dasselbe in einem Zapfen nach oben ziehend. Bei jeder Zwerchfellbewegung folgt die Adhärenz nit, wodurch diese so gut. wir: beständig in Bewegung ist. Sie erscheint recht stark gespannt und verläuft ganz nahe der vorderen Brustwand an der Einstichstelle des Thorakoskoptrokars vorbei. Aus diesem Grunde war es recht schwer, das Thorakoskop in solche Lage zu bringen, dass man einen überblick über die Adhärenz bekommen konnte. Der Einstich für den Galvanokauter wurde in der mittleren Axillarlinie im VII. Interstitium gemacht. Beim Abbrennen versuchte ich den Abbrenner zwischen die Adhärenz und die Brustwand zu bringen, damit heim Abbrennen selbst der Galvanokauter nicht mit der Pleura parietalis in Berührung kommen und dadurch Schmerzen verursachen sollte. Nur dadurch, dass ich den Abbrenner nahezu parallel mit der vorderen Brustwand führte, gelang mir dies mit einiger Mühe. Beim Abbrennen glitt indessen, wahrscheinlich auf Grund der Atembewegungen, die Adhärenz unaufhörlich vom Galvanokauter ab und schnellte zurïck, wodurch sie auch aus dem Gesichts- 
feld verschwand. Es blieb dann nichts anderes übrig, als die Adhärenz von neuem aufzusuchen und die Abbrennung aufs neue zu beginnen. Dies wiederholte sich 10-12 mal, weshalb 30-40 Minuten vergingen, bevor es schliesslich gelang, die Adhärenz vollständig abzubrennen. Ebensowenig konnte ich die Brennung an einer und derselben Stelle ausführen, was zur Folge hatte, dass die Brennfläche unnötig ausgedehnt wurde. Lm Blutung zu vermeiden, vollzog ich die Brennung mit so schwach glühendem Galvanokauter wie möglich. Während dieser ganzen Zeit hatte der Pat. nicht die geringste Schmerzempfindung. Gegen Ende des Eingriffes wurde nur ein geringes 1)ruckgefühl in der Brust verspürt, möglicherweise von der etwas gezwungenen Lage herrührend. Nach der Operation empfand der Pat. keinerlei Beschwerden.

Auf der unmittelbar nach der Operation angefertigten Röntgenaufnahme konnte man deutlich sehen, dass der obere Teil der Adhärenz frei in die Pleurahöhle herabhing, wälrend die entsprechende Spitze, Emporziehung des $Z$ werchfells, verschwunden war. Was $Z$ werchfell schien in seinem ganzen Lmfang ein ganzes Interstitiun tiefer zu stehen als zuror (l'ig. 8).

Die nächsten Tage nach der Operation hatte der Pat. recht hohes Fieber, bis über $39^{3}$. Alsdann ist die Temperatur langsam gesunken, obgleich sie in diesem Augenblick (16. II.) noch nicht normal geworden ist. Das Allgemeinbefinden ist doch gut. Kein Hautemphysem. Bei Röntgendurchleuchtung 1 Woche nach der Operation konnte man indessen konstatieren, dass ein kleineres Exsudat entstanden war, das indessen später nicht zugenommen hat.

Die nach der Operation entstandene Pleuritis hat sich nicht weiter entwickelt. Gegenwärtig ist das Exsudat so geringfügig, dass eine roryenommene Punktion negativ ausgefallen ist. Die Lunge befindet sich komprimiert im oberen Dritteil des Thorax, nach wie ror finden sich doch TB. im Auswurf. In der letzten Zeit hat Pat. an einer chronischen Appendizitis tuberkulöser Natur gelitten, derentwegen er neuerdings einer Operation unterzogen wurde. Sein Algeneinzustand ist daber in der letztea Zeit herabgesutat gewesen.

Epikrise: Der gewünschte Effekt der Operation, die Beseitigung der in Rede stehenden Adhärenz, wurde erreicht. Ein glänzendes Resultat der Operation kann man jedoch wegen der Natur des Falles gerade nicht erwarten. Die Abbrennung wurde doch nicht als einfacher Schnitt an einer Stelle ausgeführt, sondern aut Grund der Beweglichkeit der Adhärenz und der Schwierigkeit, den Galvanokauter zu manövrieren, wurde die Brennfläche an der Adhärenz recht ausgedehnt. Hierin glaube ich nämlich den Grund der Pleuritis zu sehen, die einige Tage nach der Operation entstand. Schon früher hatte der Pat. Pleuritis gehabt, und es erscheint mir wahrscheinlich, dass der thermische Roiz, welchen die Galvanokaustik darstellte, einen neuen Ausbruch derselben ausgolöst hat. Über die weitere Bedeutung derselben kann man sich noch nicht äussern; doch ist anzunehmen, dass sie relativ gutartig ist.

Fall 7. Frau A. J., 30 Jahre. Auf Anraten von dem derzcitigen Oberarzt des Sanatorium Fagered Dr. L. Franck und zusammen mit ihm operiert. Thc. pulmon. wurde Mai 1914 diagnostiziert; hatte damals sicher ein halbes Jalır bestanden. Aufgenommen in das Sanatorium Fagerel am 20. X. 1914 
und daselhst gepflegt bis zum t. Dezenber. Die ganze Zeit hindurch subfebrile Temp. Gleich nach der Entlassung bedeutend verschlimmert. Von neuem aufgenommen in das Sanatorium Fagered am 29. I. 1915 zwecks Pneumothoraxbehandlung als ultimum refugium.

Lu n g e n befund. Cber der ganzen r. Lunge mittelstarke Dämpfung, icl. C. 4 , bronchoresikulïre Respiration bis C. III und über der ganzen Hinterseite, zahlreiche mittelgrosse Rassclgeriusche, Eber der 1. Spitze leichte Dämpfung mit schwacher Resp.; am weitesten nach unten hinten einige entfernte Nebengeräusche, die als fortgeleitet gedeutet wurden! Auswurf: $\rightarrow$ TB. (zahlr.). Tem p. $38^{n}-39^{n}$. Herz o. B.; Puls 112 . Harn 0 Alb., Diazo $\frac{1}{1}$, Lrochromreaktion $\rightarrow$; Laryug it is (the. \%).

Künstlicher Pneumothorax wurde am 30. 1. angelegt (Luft). Nach der 3. Insufflation trat ein Exsudat auf, das sich nach oben bis zum Angulus scapulae erstreckte (Punktion: Exsudat klar; Esbach 28\% 4000 Leukozyten pro $\mathrm{cmm}$ ).

Nach der 6. Insufflation waren über der linken Lunge nur der Wirbel. säule entlang Rasselgeräusche zu hören. Über der rechten Lange Rasseln und bronchovesikuläre Atmung neben der Wirbelsäule. Am 29. III. war kein Exsudat nachzuweisen. Schon nach kleineren Mengen von Luft stieg der Jruck zu ziemlich beträchtlicher Höhe $(\neg 7$, Metallmanometer $)$ und es steilte sich starkes Spannungsgefühl ein. Anfang März war die Temp. afebril mit einzelnen Steigerungen. Auswurf: die Bazillen vermindert, die Menge des duswurfs verringert ron $80 \mathrm{ccm}$ auf 30. Puls 80 . Lnveränderter Lungenbefund.

16. IV. Röntgenaufnahme. Die Lunge liegt komprimiert neben der Wirbelsäule nach unten bis an das $Z$ werchfell; zwei Kavernen wurden durch eine Adhïrenz olen lateral ausgespannt gehalten (Fig. 9).

6. I. Operation im Maria-Krankenhaus in Stockholm. In clas 7. Inter sttium in ter Shapularhinie wude nach Sorokainanïsthesie der Trokar für das Thorakoskop eingefürt. Bei der darauf ausgeführten Thorakoskopie konnte min die auf der Röntgenaufnahme nachgewiesene duhärenz dutlich sehen. lic Richtung derselten war nach oben, aussen, unten und sie war in der Tähe der 2. oder 3. Wippe gerale rol der Skapula befestigt. Die Arhizrenz schien ledeatend dicker zu sein als ant der Röntyenatnahme. Zahlreiche kleine Gefässe waren durch dir: Pleura hiıdurch zu sehen. Der Trokar für den Galvanokanter wude in das 5 . Interstitium an der Forderseite gleich medial ron der vorderen Axillarlinie eingefürt. Es war sehr leicht, an der Hand des Thorakoskops den Galvanokauter auf die Adhïrenz zu richten und zu bestimmen, wo die Abbrennung erfolgen sollte. Diese wurde an derjenigen stelle der Arlhärenz ausgelührt, wo sie sich mit einer breiteren Basis an die Pleura parietalis belestigte. Migesehen ron einigen kleineren Missgeschicken mit dem Galvanokatuter betrefls iler Intensität der Glühhitze des Platinadrahtes ging das Abbrennen leicht wor sich, und binnen einiger Minuten war die dicke Adhärenz algebrannl. Lie Lunge sank unmittelbar herunler, so hass ein paar Zentimeter breiter Zwischenram zwischen den Brennflichen entstand. Darauf wurde die Pleurahöhle, gelüftet" und der durch die Abbrennung entstandene Rauch entfernt. Bei enneuter Thorakoskopie stellte sich heraus, dass ron der Brennfläche am pleuralen Teil der Adhärenz langsam Blut tropfte. Schon nach einigen Minuten hörte die Blutung spontan auf. Insgesamt dürften sich nur etwa $50 \mathrm{ccm}$ Blut in die Pleurahöhle entleert haben. Weder während der Operation noch nacl ilerselben hatte Pat. nennenswerte Beschwerden. 
Eine Temperatursteigerung an demselben Abend, wie sie in sämtlichen vorhergehenden Fällen vorkam, fand nicht statt, sondern der Zustand der Pat. war die ganze Zeit hindurch gut. Tags darauf war die Lunge im Röntgenbilde (in liegender Stellung, Fig. 10) mehr komprimiert als zuvor, und der obere Lappen endigte blind nach oben aussen mit einem breiten Zapfen. Gerade vor demselben, zwischen C. II und C. III, war ein entsprechender Zapfen ron der Thoraxwand ausgehender $=$ Reste der abgebrannten Adhärenz, zu sehen. bie Kavernen in der Lunge erscheinen möglicherweise etwas kleiner und mehr rundlich als auf der vorhergehenden Aufnahme. Es war kein Exsudat zu sehen, weil Pat. in liegender Stellung photographiert wurde. Die Luftmenge in der P'leurahöhle war vermehrt und das Mediastinum und das Herz waren ziemlich beträchtlich nach links verschoben.

Während der nächsten Tage entstand mïssig hohes Fieber mit Morgentemperatur um $38^{\circ}$, höchste Abendtemperatur $39^{3}$. Es bestand Verdacht auf Empyem, da ein unbedeutendes Exsudat nachgewiesen werden konnte. Bei der am 11. V. vorgenommenen Probepunktion wurle etwas blutuntermischte seröse Flüssigkeit gewonnen, die sich steril erwies, mutmasslich Reste der geringen Blutung bei der Operation.

Am 14. V. wurde Aspirin $0,5 \mathrm{~g} \times 3$ rerabreicht und nach dieser kleinen Dosis sank die Temperatur rasch zur Norm. Ein unbedeutendes Hautemphysem. entstand nach der Operation, aber ohne nennenswerte Beschwerden zu verursachen.

Am 15. V. wurde eine neue Röntgenaufnahme gemacht, wobei ganz veränderte Verhältnisse (Fig. 11) beobachtet wurden. Die komprimierte Lunge hatte nun eine sehr diffuse äussere Kontur, auf eine breite Verwachsung längs der hinteren Thoraxwand deutend. Von der abgebrannten Adhärenz war weder an der Lunge noch an der Pleura parietalis eine Spur zu sehen.

Von den Kavernen war die eine gar nicht, die andere undeutlich, aber wesentlich kleiner, zu sehen. Das Mediastinum und das Herz war nun weniger verscholen als rorher.

Im Sinus phrenico-costalis wurde ein ganz unbedeutendes Exsudat gefunden, das doch kaum das Diaphragma bedeckte. Am 16. V. Aufnahme in das Sanatorium Fagered.

18. V. Fieberfrei, $36,8^{0}-37,3^{0}$. Puls 64 .

21. V. Insuffl. XII -3$\left.\}-\begin{array}{r}+13 \\ +14\end{array}\right\} 500 \mathrm{ccm}$.

Pat. ist täglich mehrere Stunden auf. Im Röntgenbilde ist nunmehr kein Exsudat mehr zu sehen. Nach der Operation sank die Menge des Auswurfs von $30 \mathrm{ccm}$ auf $10-15 \mathrm{ccm}$ pro 24 Stunden. Nur während der Fiebertage Steigerung auf $20-25 \mathrm{ccm}$.

Laut Brief vom 20. VII. vom Arzt der Pat. befindet sie sich andauernd wohl. Keine messbaren Auswürfe, keine TB. im Sputum. Die Pat. ist aus dem Krankenhaus entlassen und wird poliklinisch mit Stickstoffgas-Insufflationen behandelt.

Epikrise: Die Indikation zur Operation in diesem Fall ist am nächsten übereinstimmend mit derjenigen in Fall 3. Es ist ja einleuchtend, dass die auf dem Röntgenbilde sichtbaren Kavernen nicht komprimiert werden konnten, solange die betreffende Adhärenz vorhanden war, und demzufolge waren die Aussichten auf eine 
definitive Genesung recht klein. Aus der Röntgenuntersuchung ging hervor, dass die Adhärenz sich wahrscheinlich hinten lateral, hinter der Skapula befestigte, weshalb geringe Aussicht vorhanden war, dass eine partielle Thoraxplastik sich ausführen liesse. Die Lage der Kaverne war auch derartig, dass man guten Grund hatte anzunehmen, dass in der Adhärenz keine Ausläufer zu finden sein würden. Bei der Operation nahm ich die technische Veränderung vor, die zuvor diskutiert wurde, indem ich das Thorakoskop an der Rückseite, das Galvanokauter an der Vorderseite einführte. Es war leicht sich zu orientieren wie auch den Galvanokauter zu manövrieren. Zweifellos scheint mir dieses Verfahren ein Fortschritt in technischer Hinsicht zu sein. Hier wurde eine dickere Adhärenz als in irgend einem der vorhergehenden Fälle abgebrannt, und der Fingriff ging leicht vonstatten. Nachträglich entstand eine ganz. klcine Blutung, die sicherlich absolut keine Rolle gespielt hat. Die Ursache derselben ist dunkel; möglicherweise ist der letzte Rest der Adhärenz nicht abgebrannt worden, sondern ist abgerissen, wodurch diese kapilläre Blutung entstanden ist.

In diesem Falle endlich entfernte ich zum Unterschied von früheren Fällen nach der Operation den Rauch aus der Pleurahöhle. Hier trat auch nach der Operation keine Temperatursteigerung ein, was in allen übrigen Fällen der Fall war. Möglicherweise kann in dieser Beziehung die Entfernung der Verbrennungsgase eine Rolle spielen. Diese ,Lüftung“" des Pleuraraumes hatte auch eine Vermehrung des Luftquantums zur Folge, was auf der Röntgenaufnahme durch die starke Verschiebung des Mediastinums und des Herzens zum Ausdruck kam.

Auf die Menge des Auswurfs ist die Operation bereits von Einfluss gewesen, indem dieselbe von 30 auf $10-15 \mathrm{ccm}$ pro 24 Stunden gesunken ist. Dies erfolgte bereits am Tage nach der Operation. Auch in diesem Falle wird innerhalb eines Monats ein völliges Aufhören von Tuberkelbazillen und Auswurf erreicht.

Gleichfalls dürfte man sicher sein können, dass in der abgebrannten Adhärenz kein Ausläufer der Kaverne vorhanden gewesen ist. In diesem Falle wäre längst ein Empyem mit seinen schweren Folgen entstanden. Für den Fall, dass die andere Lunge sich nicht verschlimmert, dürfte man in diesem Falle auf ein gutes Resultat rechnen können.

Fall 8. E. G., Arbeiter, 28 Jahre. Serafimerlazarett V. 1915. Nr. 107. Auf Anraten von und zusammen mit dem oberarzt des Sanatoriums Löt, Dr. Löw en hi $\mathrm{l}$ lm, operiert.

Im Herbst 1914 fing der Pat, der früher immer gesund war, zu busten an. 
Am 2. XII. erkrankte der Pat. heftig mit Fieber bis $40^{\prime \prime}$, Stichen in der linken Seite sowie mit Symptomen von Pneumonie in dem unteren Teil der linken Lungenlobe. Eine Resolution in der gewöhnlichen Zeit trat nicht ein, und nach einiger Zeit wurden TB. im Sputum des Pat, nachgewiesen. Der Pat. wurde am 2.5. Februar in Sanatorium Löt aufgenommen, wo sein Zustand folgender war:

Allgemcinzustand ziemlich gut. Temp. zwischen $38^{0}-38.5^{\circ}$. Rechte Lungenspitze $n$. t. sowie vereinzelt geringes Rasseln im I. und II. Interstitium. Linke Lunge: auf der Rückenseite D. 5, an der Spitze abwärts bis zur Mitte der Skapula dann 1. 3. In der Vorderseite D. 5, über der Spitze. weiter unten D. 3. Bei Auskultation überall zahlreiches Rasseln, das Atmungsgeräusch deckend.

Am 5. III. wurde mit Pneumothoraxbehandlung begonnen und während der folgenden Ionate fortgesetzt. In dieser Zeit keine Veränderung im Allgemeinbefinden des Pat. Die ganze Zeit TB. im Sputum.

Der Pat. kam am 31. V. 1915 in die med. Klinik II des Serafimerlazarettes. Der Zustand war ziemlich gut. Die Temperatur hielt sich jedoch auf ungefähr $38^{\circ}$ morgens und $39^{\circ}$ abends. Der Pat. litt an recht intensivem Husten mit einer ziemlich wechselnden Sputummenge zwischen 90 und $40 \mathrm{ccm}$ pro Tag. Bei der Lntersuchung der Brustorgane ergeben sich keine krankhaften Veränderungen an der rechten Lunge. Üher der linken hypersonor-tympanitischer Ton ausser am weitesten ab- und rückwärts, wo sich Dämpfung befindet. Bei der Auskultation hört man geschwächte Atmung von etwas variierender Art sowie über den oberen Teilen zahlreiche harte Rasselgeräusche. Auf der Vorderseite auf einem etwa kinderhandgrossen Gebiet im III. und IV. Interstitium zahlreiche Reibegeräusche vorhanden. Bei der Probepunktion klar seröses Exsudat. Am 1. VI. Röntgenaufnahme. Linksseitiger Pneumothorax. Die Lunge ist in ihrem oberen medialen und unteren lateralen Teil kollabiert. Dieselbe wird von zwei ziemlich ausgedehnten Adhärenzen am oheren Teil der lateralen Brustkorbwand festgehalten, die obere in der Gegend ron C. I und C. II, die untere von C. II bis C. IV. Haselnussorosse Kaverne in der Lunge. Das Exsudat geht bis C.V, an der Vorderseite gerechnet. Am selben Tage wurde Thorakoskopie mit Einstich im IX. Interstitium in der Skapularlinie ausgeführt. Das Gesichtsfeld war stark begrenzt. Nach oben und lateral wurde die Aussicht durch breite Filirinmemhranen gesperrt. Sämtliche Pleuraflächen waren stark gerötet mit hicr und da weissglänzenden Fibrinbelägen. Die auf der Röntgenplatte sichtharen Verwachsungen konnten nicht dentlich unterschieden werden. Am Grunde geringe Nenge von klarem serösem Exsudat. Im Sputum zahlreiche TB. und elastische Füden. Der Pat. litt an periodischer Heiserkeit, die Stimmbänder waren gerötet. aber ohne augenscheinliche tuberkulöse Verändemungen.

Von ïbrigen Organen nichts Bemerkenswertes.

Im Juni wurden die Insufflationen mit Luft in so grosser Ausdehnung, wie sie der Pat. aushalten konnte, fortgesetzt, gewöhnlich mit $500 \mathrm{ccm} 2 \mathrm{mal}$ in der Woche.

Am 1. Vli. neue Röntgenaufnahme (Fig. 12). Die Lunge ist recht gut komprimiert, ist aber an der lateralen und oberen Thoraxwand mit drei etwa fingerdicken Strängen befestigt. Die Befestigung der obersten Adhärenz scheint hoch oben oberhalb der ersten Rippe zu liegen. die der übrigen gerade vor der zweiten und dritten Rippe lateral und etwas nach hinten. Die oberste ist am schmälsten, die unterste am dicksten. Das Exsudat ist verschwunden. 
Mitten in der Lunge erscheint ein etwa haselnussgrosser hellerer Fleck, der auf eine Kaverne schliessen lüsst.

Am 2. VII. Operation. Der Trokar des Thorakoskops wurde im IX. Interstitium in der Skamblulinie nach lokaler Anästhesie mit halbprozentiger Norokainlösung eingeführt. Bei der Thorakoskopie traten die beiden unteren Adhärenzen besonders deutlich herror, jedoch wohl kaum so massiv, wie man nach Röntgen glauben sollte. Die Farbe ist blass-rosa, eine mässige Menge Gefässe andeutend. Die Lunge hat deutlich verdickte Pleurafläche und besonders nach unten beträchtliche Fibrinbeläge. Der Einstich für den Galvanokauter wurde im $V$. Interstitium in der vorderen Axillarlinie vorgenommen. Das Manöverieren desselben ging leicht vonstatten.

Die Abbrennung wurde zunächst an der am weitesten nach unten gelegenen gröbsten Adhärenz ohne nennenswerten Schmerz leicht und rasch an der schmalsten Partie derselben ausgeführt. Darauf wurde die Abbrennung der oberen rorgenommen, was auch keine besonderen Schwierigkeiten bereitete. Einige Bluttropfen sickerten von der Brenufliche an der unteren Adhärenz hervor, sonst waren bei der Thorakoskopie keine schädlichen Folgen des Eingriffes zu entdecken. Die oberste Adhürenz konnte ich nicht ermitteln, weil die Lunge nicht genügend komprimiert war. Die Pleurafläche wurde nach der Operation gelüftet und aller Rauch entfernt.

Nach der Operation entstand keine Temperatursteigerung am selven Tage, und abgesehen ron Schmerzen in den Punktionswunden bot der Zustand des Pat. nichts Bemerkenswertes. Es entwickelte sich ein mässig grosses subkutanes Emphysem. Nach einigen Tagen stieg das Fieber allmählich um etwa einen Grad und hielt sich zwischen $39^{0}$ und $39,5^{9}$. Am 6. VII., also $t$ Tage nach der Operation, wurde eine neue Röntgenaufnahme gemacht (Fig. 13). Auf derselben traten heide Abbrennungsflächen hervor, die untere ungefähr $2 \mathrm{~cm}$, die obere $1 \mathrm{~cm}$ breit. Etwas oberhalb an der parietalen Wand sind, wenn auch schwach. die entsprechenden abgeschnittenen Prramiden, die die Ansatzpunkte der peripheren Teile der Adhärenzen bezeichnen, sichtbar. Die oberste und schmälste dahïrenz fand sich vor, hatte sich aber wesentlich gestrecht.

Am 9. VII. konnte man eine leichte Dämpfung am weitesten nach unten auf der linken Seite sowie Reibegeräusche konstatieren. Die Probepunktion ergab eine klare seröse Flüssigkeit.

Vom 10.-.-16. VII. litt der Pat. an einer recht beschwerlichen akuten Pharyngitis, dic auch seine Krälte herabsetzte. Sein Appetit war nicht schlecht. Keine Senkung der Temperatur, in diesen Tagen für Aspirin $1 / 2 \mathrm{~g} \times 3$.

Am 14. Vil. erneute Insufflation von $350 \mathrm{ccm}$ Luft. Druck vorher $\div 6 \mathrm{~cm}$, nachher $+14 \mathrm{~cm} \mathrm{H} \mathrm{H}_{2} \mathrm{O}$. Der Auswurf des Pat. hat sich doch etwas, und zwar auf ungefähr $50 \mathrm{~cm}$ pro Tag rerringert. TB. sind jetzt nicht gefunden worden.

Am 19. VII. Röntgenaufnahme. Die Lunge ist jetzt noch mehr komprimiert und macht den Eindruck, als ob sie an einer langen, schmalen Adhärenz hinge. Die Kaverne kann man nicht sehen. Am Grunde der Pleurahöhle ein kleines Exsudat, das sich nach der 6. Rippe an der Vorderseite (Fig. 1t) hinanf erstreckt.

Am 20. VII. wurde die Abbrennung der letzten Adhärenz mit dem Trokar des Thorakoshops im selben Interstitium wie vorher ausgeführt. Der Galvan`kauter wurle an der Vorderseite in ein Interstitium höher hinauf als früher eingeführt. Bei der Thorakoskopie erhielt man mehrere sehr interessante Auskünfte. Die von den vor 18 Tagen gemachten Abbrennungen zurickgebliebenen Wunden waren fast geheilt und bildeten zirkelrunde Narben, von einem weissen 
fibrinen Wall umgeben. Im Zentrum braunrote Schorfe. Sowohl all der Lunge wie auch an der parietalen Wand waren dieselben im gleichen Niveau wie die umgebenc Fläche. Ausserdem waren alle Pleuracbenen stark gerötet und entzündet, hier und da mit Fibrinbelägen, besonders an den unteren Teilen der Lunge. Ausserdem konnte man vereinzelte frische Tuberkeln sehen, die wie „Mückenstiche in Miniatur" erschienen. Nach oben erschien die zurückgebliebene schmale Adhärenz, ganz nach oben in der "Pleurakuppe" befestigt. Dieselbe ist schmäler, aber von bedeutend dunklerer Farbe als die frühere. Die Abbrennung ging besonders leicht, schnell und schmerzfrei vor sich; es wurde aber recht starke Glühe am Galvanokauter angewand, weshalb an der peripheren Abbrennungsstelle eine nicht so unbedeutende Blulung entstand. Dadurch, dass die glühende Platinnadel ganz nahe an die Abbrennungsfläche gebracht wurde, wurde die Blutung schnell zum Aufhören gebracht. Es gelang mir nicht, den zentralen Teil der Adhärenz zu sehen. Nach dieser Operation entstand trotz der Blutung in den nächsten Tagen keine Verschlimmerung. Auf der Röntgenaufnahme konnte man sehen, wie die Lunge auch weiter zusammengesunken war. Nach oben war, ein kleiner Zapfen, der abgebrannten Adhärenz entsprechend, zu sehen. Das Exsudat ist etwas vermehrt, indem es bis an das $V$. Interstitium reicht (Fig. 15).

Nach der letzten Operation scheint sich der Appetit des Patienten wesentlich zu verbessern. Während des ganzen vorherigen Krankenhausbesuchcs ging das Gewicht des Pat. konstant $\mathrm{um}$ im ganzen 6-7 $\mathrm{kg}$ herunter; eine Woche nach der lctzten Operation war eine. Gewichtsvermehrung von $11 / 2 \mathrm{~kg} \mathrm{zu}$ verzeichnen. Der Auswurf zeigt auch eine wesentliche Verringerung, variierend zwischen 50 und $25 \mathrm{ccm}$ pro Tag. Die Temperatur ist jedoch andauernd hoch: $38^{\circ}-39^{\circ}$. Wiederholte TB.-Untersuchungen im Sputum ergahen ein negatives Resultat.

Am 31. VII. wurde der Patient zwecks fortgesetzter Pflege im Sanatorium Löt entlassen ${ }^{1}$ ).

E pikrise: Als dieser Fall zuerst ins Krankenliaus kam, waren die Aussichten für eine erfolgreiche Abbrennung der Adhärenzen recht gering. Die Verwachsungen schienen allzu verbreitet $z u$ sein. Bei der Thorakoskopie konnte man sich nicht einmal über die Lage dẹ Adhärenzen orientieren. Durch fortgesetzte Pneumothorax-Ber handlung wurden die Adhärenzen gestreckt und erheblich schmäler. Bei der Operation selbst war die Orientierung nicht schwer, und die eigentlicht Abbrennung ging leicht vonstatten. Die Einwirkung davon machte sich bald bemerkbar, indem sich die Menge des Auswurfs allmählich verminderte und die Tuberkelbazillen aus dem Auswurf verschwanden. Der allgemeine Zustand des Patienten verschlimmerte

1) Nachtrag zur Korrektur: Laut späteren Nitteilungen von Ende September hat sich der Pat. wieder verschlechtert. Das Exsudat ist etwas vermehrt, aber sonst keine Symptome von den Brustorganen. Albumin 1st in grossen Mengen im Urin aufgetreten, sowie intensive Diarrhöen. Ende Oktober ist der Pat. rlagegen bedeutend verbessert, ohne Diarrhöen und Albumin im Urin, sowie beinahe fieberfrei. Das Exsudat ist zum grössten Teil zurückgegangen. Die Junge ist vollständig komprimiert. Der Zustand des Pat. gilbt jetzt betreffs les Fndresultats die besten Hoffnungen. 
sich, was teils auf ein Wiederaufflammen seiner Pleuritis, teils auf eine zustossende, recht schwere akuto Pharyngitis zurückzuführen war.

18 Tage nach dieser Operation wurde die zweite vorgenommen, bei welcher die letzte und schmälste Adhärenz abgebrannt wurde. Die Thorakoskopie war diesmal mehr als gewöhnlich von Interesse. Es zeigte sich teils, dass die Operationswunden von der vorigen Operation fast ausgeheilt waren, teils auch, dass eine frische Tuberkeleruption auf den Pleuraebenen als wahrscheinliche Folge des Eingriffes entstanden war. Die Operation betreffend handelte es sich hier um eine erheblich blutreichere Adhärenz als die vorherigen. Eine nicht so unbedeutende Blutung entstand; es zeigte sich jedoch, dass man einer solchen Komplikation nicht machtlos gegenübersteht. Durch Kauterisierung der blutenden Fläche wurde die Blutung recht leicht gestillt. Über die Einwirkung auf das Resultat der Pneumothoraxbehandlung im grossen ganzen sich zu äussern, ist es noch zu zeitig.

Fall 9. Frau G. C., 40 Jahre. Serafimerlazarett 1915. Abt. I. Nr. 397. Oberarzt Prof. I. H o l m gren.

Die beiden Eltern und ein Bruder an Lungentuberkulose gestorben. Im Herbst 1912 wurde Lungentuberkulose diagnostiziert und die Pat. ist seit dieser Zeit während verschiedener Perioden in Sanatorien und Krankenhäusern gepflegt. Dic Pat. wurde wegen Pneumothoraxbehandlung am 6. V. 1915 ins Serafimerlazarett aufgenommen. Der allgemeine Zustand der Pat. war ziemlich gut. An der ganzen rechten Lunge, besonders an der oberen Hälfte, war eine erhebliche Dämpfung. Das Atmungsgeräusch war geschwächt von zahlreichen mittelblasigen konsonierenden Rasselgeräuschen bedeckt. Keine deutlichen Kavernensymptome. An der Vorderseite der linken Lunge schwache Dämpfung bis C. III, an der Rückenseite bis Spin. scap. Sputa ca. $70-80 \mathrm{ccm}$ täglich. Auch hier konsonierende Rasselgeräusche. Zahlreiche TB. im Sputum.

Am 12. V. wurde mit Pneumothoraxbehandlung begonnen, welche ohne störende Komplikationen im Laufe des Sommers fortschritt. Bei Röntgenuntersuchung Anfang August war die rechte Lunge beinahe ganz kollabiert, aber ziemlich breit mit dem Diaphragma zusammengewachsen. Lateral aufwärts, mit C. III parallel verlaufend, war eine schwache strangförmige Adhärenz mit etwas diffusen Konturen zu sehen (Fig. 16). Gleich unter ihrer Anheftung an der Lunge sah man eine Kaverne von der Grösse einer Mandel. Kein Exsudat. Fortwährend TB. im Sputum. Die Menge $25-40 \mathrm{ccm}$.

Am 23. VIII. Operation. Der Trokar für die Thorakoskopie wurde im Rücken, etwa in der Skapularlinie, eingeführt. Bei der Thorakoskopie waren die Pleuraflächen normal.

Die Lunge war ziemlich gut komprimiert und ohne scheinbare Luftmenge. Vom obersten Teile des untersten Lappens sah man eine lange Adhärenz schroff aufwärts und rückwärts an der Brustwand haften. Sie hatte doch nicht die Form eines kompakten Stranges, sondern einer dünnen Membran mit verdicktem Zentrum in der Längsrichtung der Lunge gehend.

Erst versuchte ich mit der Thorakoskopie die Lage der Adhärenz zu bestimmen, dann brachte ich den Trokar für den Galvanokauter ungefähr in der 
vorderen Axillarlinie im X. Interstitium an. Der Galvanokauter wurde dann in rer Richtung gegen die Adhärenz eingeführt. Dies gelang so gut, dass bei der für die Abbrennung notwendigen Thorakoskopie der Galvanokauter sich schon in Kontakt mit der Adhärenz auf ihrem schmälsten Teile befand. Man hatto nur das Brennen gleich zu beginnen. In einer Minute war man damit fertig, ohne einen Tropfen Blut und ohne Schmerzen für die Pat.

Die Pat. fühlte sich nach der Operation gut. Um Hautemphysem zu vermeiden, wurde ein Teil der Luft zu negativem Druck ausgezapft. Am selben 'Tage hatte die Pat. am Abend eine Temperatursteigerung bis $38,5^{0}$. Sie bekam trotz der Luftabziehung ein mässiges Hautemphysem, aber sonst war der Zustand ganz gut. Schon am folgenden Tage war die Temp. dieselbe wie vor der Operation.

Am 27. VIII. Röntgenuntersuchung. Beim Vergleich mit Photo vor der Operation fand man, dass die Adhärenz verschwunden war (Fig. 17). Ein unbedeutender zapfenförmiger Schatten in der Nähe der 3. Rippe an der parietalen Wand gerade gegenüber war das einzige, was man davon sehen konnte! An dem unteren Lungenlappen konnte man keine Spuren davon entdecken. Dieser Lappen schien viel mehr mit Luft gefüllt wie vorher, weshalb ihre Kontur sehr diffus war. Auch bekam man keinen Eindruck von der früher gesehenen Kaverne. Während der folgenden Tage wurde der allgemeine Zustand der Pat. rerbessert und am 30. VIIl. wurde wieder mit einer Stickstoffbehandlung begonnen.

Binnen 2 Wochen wurde die Lunge rollstindig komprimiert: woht wr. gleichbar mit z. B. Fall 3, Fig. 3. Auch übrigens ist die Pat. verbessert.

Epikrise: Obgleich dieser Fall sehr einfach vorfällt, so sind doch einige beachtenswerte Sachen damit verbunden. Der Fall war derart, wo eine Kaverne durch eine strangförmige Adhärenz zu kollabieren verhindert wurde, und war für eine Abbrennung sehr verlockend. Zuerst war ich doen sehr bedenklich, weil die Lage der Kaverne zur Adhärenz derart war, dass man mit der Möglichkeit eines Ausläufers aus der Kaverne in die Adhärenz zu rechnen hatte. Ein Öfnen der Kaverne in die Pleurahöhle hinein könnte die Folge werden. Erst bei der Thorakoskopie wagte ich mich für die Abbrennung zu bestimmen. Bei derselben sah man, dass die hinderliche Adhärenz grösstentcils aus einer ganz dünnen Membran bestand, was natürlich dem obengenannten Verdacht höchstens widersprach. Mit der Orientierung und der Abbrennung war man bald fertig. Um Hautemphyseme zu vermeiden, zapfte ich wie in anderen Fällen die Luft aus der Pleurahöhle zu negativem Druck ab. Den erwünschten Erfolg erhielt ich nicht. In wenigstens ebenso hohem Grade wie in früheren Fällen entstand diese ungefährliche, aber schmerzvolle Komplikation. Bei Röntgen konnte man eine beachtenswerte Erweiterung der Lunge konstatieren. Der Fall zeigt also, dass man keinen grossen Nutzen von der Gasabziehung hat, sondern dass es vor allen Dingen gilt, den Hustenreiz zu bekämpfen. Schliesslich ist es schon möglich zu sagen, dass kein Ausläufer aus der Kaverne bei der Abbrennung 
berührt oder geöffnet worden ist. Übrigens hätte wahrscheinlich ein so grosses Hautemphysem nicht auftreten können, wenn eine Kommunikation mit dem Bronchialbaum entstanden 'wäre. Bei der folgenden Pneumothoraxbehandlung ist man berechtigt, einen sicheren Erfolg auch von dieser Operation zu erwarten.

Bei einer Zusammenfassung der Resultate der Operationen in diesen Fällen will ich zunächst die zwei ersten Fälle als blosse Versuchsoperationen ausschliessen. Von den übrigen vier ist das Resultat in Nr. 3 vorzüglich gewesen. In Nr. 4 entstand eine Komplikation, weshalb ich die Operation unmittelbar abbrach in der Absicht, sie später wieder aufzunehmen. Der Pat. kam aber nicht zurück, weshalb dieser Fall kaum mitgezählt werden kann. Im Fall 5 ist es sehr schwer, den Effekt zu beurteilen. Hier waren die Verwachsungen bedeutend grösser, als der Röntgenbefund erwarten liess. Es wurden sehr ausgebreitete Adhärenzen, die sich nach unten erstreckten, abgebrannt, während gerade die strangförmigen Adhärenzen, die auf der Röntgenaufnahme zu sehen waren, nicht erreicht wurden. Doch macht der spätere Verlauf es wahrscheinlich, dass der Eingriff von Nutzen gewesen ist.

Im Fall 6 wurde eine strangförmige Adhärenz abgebrannt, welche die Lunge an das Zwerchfell fixiert hielt. Dieselbe hinderte die Lunge in ihrem ganzen Umfang zu kollabieren, und ferner wurde die Lunge dadurch in steter Bewegung gehalten und erreichte demnach nicht die Immobilisierung, auf welche die Behandlung abzielte. Welche Wirkung auf das Endresultat der Pneumothoraxbehandlung: ausgeübt. wird, darüber kann man sicht nicht äussern. Im Fall 7 wage ich, auf ein glänzendes Resultat zu hoffen, wenn die gesunde Lunge nicht angegriffen wird.

Im Fall 8 ist der Zustand noch ungewiss. Hierbei ist eine Abbrennung in bedeutend grösserer Ausdehnung als in irgend einem früheren Fall vorgenommen worden, und es will mir scheinen, dass man sich hier der äussersten Grenze dessen genähert hat, was die Methode bieten kann. Die Kompression der Lunge ist jedoch nunmehr vollständig; Tuberkelbazillen im. Auswurf haben aufgehört, und die weitere Besserung des Pat. scheint gegenwärtig von dem Verlauf der recht hartnäckigen Pleuritis abzuhängen, die nach der Operation zugestossen ist.

Die Ungelegenheiten, die im Zusammenhang mit der Operation entstanden sind, sind in drei Fällen kleine Blutungen, die niemals so gross gewesen sind, dass sie irgendwelche klinische Symptome ergeben konnten, ferner in drei Fällen eine akute Pleuritis exsudat. 
In den letztgenannten drei Fällen existierte kurz vorher eine Pleuritis, die bei der Operation keine klinischen Symptome zeigte. Bei der Thorakoskopie ist jedoch eine gerötete, entzündete Fläche konstatiert worden mit hier und da weissglänzenden Fibrinbelägen.

Von Interesse ist, dass in einem Fall (8) eine Thorakoskopie 14 Tage nach einer solchen Abbrennung ausgeführt worden ist, und dass ich darin deutliche frische Tuberkelbazillenknoten gefunden habe. Der Verlauf dieser Krankheit ist in zwei Fällen ein recht bescheidener gewesen, da in keinem derselben zu Thorakozentes gegriffen zu werden brauchte; im dritten (8) ist die Zeit zu kurz, um cin Urteil fällen zu können.

Wie aus dem oben Angeführten hervorgeht, liegt das Hauptgewicht bei diesen Operationen teils darin, dass man sich bei der Thorakoskopie in der Pleurahöhle orientieren kann, teils dass man hierbei den Galvanokauter manövrieren kann. Beides erfordert Übung, und bevor man Versuche an Menschen macht, ist es zweckmässig, sich erst am Phantom und an Tieren zu üben. Wahrscheinlich ist recht fleissige Übung erforderlich. Ich werde daher in aller Kürze einige allgemeine Erfahrungen über die Orientierung bei der Thorakoskopie und einige technische Details bei der Abbrennung mitteilen.

Bei pleuritischen Exsudaten und bei Pneumothorax habe ich die beste Übersicht gewonnen, wenn ich das Thorakoskop an der Vorder- oder Rückseite des Brustkorbes rechtwinklig zur Iängsrichtung der Lunge eingeführt habe.

Da das Prisma am Thorakoskop seitlich sitzt, kann man den oberen oder unteren Teil der Lunge, das Zwerchfell und die Pleura parietalis sehen lediglich durch Herumdrehen des Thorakoskops. Um vordere oder hintere Abschnitte der Lunge zu Gesicht zu bekommen, hat man das Thorakoskop tiefer einzuschieben oder herauszuziehen. Indem man-das Thorakoskop nur in diesen beiden Richtungen bewegt, kann man im allgemeinen nahezu die ganze Pleurahöhle übersehen. Es verhält sich annähernd wie ein drehbarer Objekttisch an einem Mikroskop. Die Bewegung in der dritten Richtung, wobei man sich der Lungenoberfläche nähert oder von derselben entfernt, dient dazu, Details zu vergrössern oder durch Verkleinerung einen Überblick über grössere Flächen zu gewinnen.

In gleicher Weise muss man beim Manövrieren des Galvanokauters vorerst praktische Übungen am Phantom oder an Tieren vornehmen. In der Pleurahöhle pflege ich zuerst mit dem Thorakoskop Lage und Richtung der Adhärenz im Verhältnis zur Brustwand zu bestimmen und berechne dann, wie beim Einstich von aussen die- 
selbe am leichtesten zu erreichen ist. Ist die Lunge gut komprimiert und findet sich nur eine einzige Adhärenz, so sind die Schwierigkeiten bei der Orientierung gering. Finden sich mehrere oder membranartige Adhärenzen, so steigern sich die Orientierungsschwierigkeiten in sehr hohem Grade. Für solche Fälle ist es nicht möglich, irgendwelche Vorschriften zu geben; sondern man muss sich dann auf die eigene Erfahrung stützen.

In den hier publizierten Fällen habe ich im allgemeinen das Thorakoskop und den Abbrenner zwischen der Mamillar- und der mittleren Axillarlinie, aber in verschiedenen Interstitien, eingeführt. Dies hat den Vorteil, dass sich dann beide Instrumente auf derselben Seite des Patienten befinden. Der Nachteil ist, dass sich dieselben leicht gegenseitig in den Weg kommen; es ist jedoch von besonders grosser Bedeutung, dass der Abbrenner nicht in seiner Beweglichkeit gehindert wird. Bei Untersuchung am Skelett bin ich zu dem Resultat gelangt, dass man das Thorakoskop ebensogut von hinten oder von der Seite würde einführen können. Mutmasslich muss man die nämlichen Orientierungsmöglichkeiten gewinnen. Der Trokar für den Abbrenner muss jedoch an der Vorderseite singeführt werden. Diesen muss man in der Mehrzahl der Fälle in mehreren Richtungen bewegen, und die besten Bedingungen hierfür finden sich ohne Zweifel an der Vorderseite auf Grund der Stellung der Rippen und der grösseren Breite der Interkostalräume daselbst, wovon man sich leicht durch einen Blick auf das Skelett überzeugen kann. Bei Skelettversuchen ergibt sich ein Unterschied in der Beweglichkeit des Abbrenners an der Vorder- und Rückseite von $40-50^{\circ}$. In den Fällen 7,8 und 9 habe ich dies Verfahren angewandt und gefunden, dass dasselbe entschieden vorzuziehen ist.

Hinsichtlich des Zustandes der Lunge sind die Verhältnisse am günstigsten, wenn die Lunge vollständig atelektatisch ist. Dann sind die Adhärenzen am stärksten gedehnt, der Raum am grössten und die Bedingungen für eine Orientierung am günstigsten. Die Befestigung der Adhärenzen an verschiedenen Stellen der Brustwand bedingt eine variierende Technik mit verschieden grossen Schwierigkeiten an verschiedenen Stellen. Am leichtesten zugänglich für den Abbrenner sind wahrscheinlich die strangförmigen Adhärenzen nach oben aussen sowie nach unten nach dem Zwerchfell. Keine besonderen Schwierigkeiten bieten die Adhärenzen in der Lateralregion dar. Die grössten Schwierigkeiten bereiten die vorderen Adhärenzen, weil der Abbrenner dann von der lateralen Region aus eingeführt werden muss, wo die Beweglichkeit des Instrumentes geringer ist. Dies sind doch mehr oder weniger theoretische Erwägungen, welchen bisher keine 
praktischen Erfahrungen zugrunde liegen. Bei der eigentlichen Brennung spielt die Glühe am Galvanokauter eine gewisse Rolle. Bei schwacher Glühe ist die Gefahr für Blutung bedeutend geringer; bei starker ist das Gegenteil der Fall. Hieraus geht hervor, dass man eine so schwache Glühe wie möglich anwenden soll. Eine andere Ungelegenheit entsteht hierbei dadurch, dass der Platinadraht an der Adhärenz festklebt. Die geringsten Bewegungen verursachen alsdann ein schmerzhaftes Ziehen in der Adhärenz, das während der Operation sowohl den Patienten wie auch den Operateur leicht beunruhigen kann.

Schliesslich möchte ich betonen, dass bei dieser Methode der mehr oder weniger gute Ernährungszustand des Kranken eine recht wesentliche Rolle spielt. Die Möglichkeit, den Abbrenner zu manövrieren, ist bei fettleibigen Individuen erheblich eingeschränkt. Auch eine grosse Mamma kann technisch Schwierigkeiten bereiten. Eigene diesbezügliche Erfahrungen stehen mir indessen nicht zu Gebote.

Wie aus dem Vorhergehenden hervorgeht, findet sich in einem Fall (Nr. 4) ein handgreiflicher Untersichied in dem Ergebnis der Röntgenuntersuchung und der Thorakoskopie. Dies hat mich veranlasst, in einigen Fällen von strangförmigen Adhärenzen, wo Sektion ausgeführt wurde, die Zuverlässigkeit und Vollständigkeit des Röntgenbefundes zu kontrollieren.

Fall I. I. L. H., geb. 10. II. 1894, gest. 7. IX. 1914. Sundsvalls Sanatorium, Nr. 62 und 178, 1913. Oberarzt Daniels son.

A n a mnese. Die ersten Erscheinungen der Krankheit, Husten, Fieber, Stechen in der Brust usw., datieren seit September 1912.

Bei der Aufnahme in das Sanatorium findet sich mittelstarke Dämpfung über der oberen Hälfte der 1. Lunge mit zahlreichen, grossen, klingenden Rasselgeräuschen und Reibegeräuschen über der ganzen Lunge. An der Spitze der r. Lunge nur unerhebliche Veränderungen. Am 14. IV. 1913 begann die Stickstoffbehandlung. Am 21. IV. 1914 die letzte Einblasung von $900 \mathrm{ccm}$. Bei Röntgenuntersuchung findet man vollständigen Pneumothorax. Die Lunge ist etwa zur Hälfte kollabiert mit zwei deutlichen Kavernen. Der Oberlappen ist aufwärts durch eine ziemlich breite und undeutliche Adhärenz an der Thoraxwand befestigt. Der Umriss des Oberlappens erscheint etwas rundlich (nicht spitz ausgezogen, wie in den Fällen 3 und 4). Am 23. IV. 1914 Bluthusten mit nachfolgendem, langwierigem Fieber. Die Stickstoffbehandlung wurde aus diesem Grunde abgebrochen. Exitus letalis 7. IX. 1914. Pneumothorax -Dauer 17 Monate.

Bei der Sektion am 8. September 1914 findet man, dass die linke Pleura 200-300 ccm klares hellgelbes Exsudat enthält und im übrigen mit Gas gefüllt ist. Die 1. Lunge liegt gut komprimiert entlang der Wirbelsäule von einer bede ut end verdickten glatten und glänzenden Pleura überzogen. Die Lunge adhäriert hauptsächlich oben, aber auch lateral sieht 
man ein paar strangförmige fadendünne Adhärenzen nach der Brustwand verlaufen. Der Apex. pulmon. sin. ist mittels fünf rundlichen, sehnigen, feineren und gröberen Adhärenzen von etwa $5-6 \mathrm{~cm}$ Länge an der 1. (event. 2.) Rippe befestigt. Es sieht aus wie eine Hand mit fünf gespreizten Fingern zwischen rer Lungenspitze und der Brustwand. Die gröbste Adhärenz ist von der Dicke einer dünneren Bleifeder, die übrigen vier sind dünner, bis fadendünn. Alle Stränge sind. rund, sehnig, weissglänzend und schwer zu durchschneiden. Es hat den Anschein, als ob Gefässe in alle Adhärenzen hinausgehen. Am weitesten nach unten nach dem $Z$ werchfell hin findet sich ein schmaler Ausläufer, der die laterale Ecke der Lunge an das Zwerchfell fixiert.

Beim Herausnehmen der Lunge sieht man, dass die Spitze eingenommen wird von einer mehr als walnussgrossen Kaverne, gefült mit einer schmierigen, eiterähnlichen Masse. Die Wand der Kaveme ist dick, fest und sehnig, und ron der pleurablekleideten äusseren Oberfläche dieser Wand strahlen die Adhärenzen gegen die Brustwand aus, sämtlich dicht nebeneinander am viszeralen Blatt der Pleura befestigt. Makroskopisch sind keine Auslänfer der Kaverne in die Adhärenzen hinein sichtbar. Die übrigen Teile der Lunge sind ron derselben festen Konsistenz wie die herausgenommene Partie, die beim Einschneiden eine grauweisse, vollständig luftleere, bindegewebig indurierte Schnittfläche mit hie und da eingesprengten schieferfarbenen Partien zeigt.

Die übrigen Organe wurden nicht gerührt.

In diesem Fall konnte man bei der Röntgenuntersuchung nicht mehr als eine einzige Adhärenz sehen. Bei der Sektion fanden sich fünf Adhärenzen, wenn auch mehrere derselben nicht dicker waren als ein dicker Bindfaden. Es ist doch nicht wahrscheinlich, dass sie bei einem eventuellen endopleuralen Eingriff ein ernsteres Hindernis verursacht haben würden. Ebensowenig fand sich ein Ausläufer der Kaverne in die Adhärenzen hinein, nicht einmal bei mikroskopischer Untersuchung.

Fall II. Frau E. 0., 32 Jahre. Krankenhaus Sabbatsberg (die Krankengeschichte von Dr. Wetterdal mitgeteilt). Hämoptyse zum erstenmal im Februar 1913, dann eine neue Lungenblutung im September desselben Jahres; wurde in der Zwischenzeit bis 12. IX. 1913 in einem Sanatorium gepflegt. Nach der Rückkunft Verschlimmerung, Husten, Nachtschweisse, Abmagerung. Aufgenommen in das Krankenhaus Sabbatsberg am 17. X. 1913. Allgemeinzustand herabgesetzt. Über der 1. Lunge Dämpfung vorne bis zur 4. Rippe, hinten bis zur Mitte der Skapula. Bronchialatmung über den gedämpften Partien mit Massen ron Rasselgeräuschen. L. Lunge: leichte Dämpfung über der Spitze, kein Rasseln. Zahlreiche TB. im Auswurf. Pneumothoraxbehandlung wurde am 24. X. 1913 eingeleitet und ging ohne Schwierigkeit vonstatten. Bedeutende Eesserung. Entlassen am 7. V. 1914 in ambulatorische Behandlung. Seit Juli $191 \pm$ Diarrhöe. Im Herbst hin und wieder Stechen in der 1. Seite. Aufnahme von neuem am 6. XI. mit einem recht grossen pleuritischen Exsudat von serösem Charakter. Am 15. XI. Bluthusten. Am 26. XI. plötzlich Exitus letalis. Daner der Pneumothoraxbehandlung also 12-13 Monate.

$\mathrm{R}$ ö $\mathrm{n}$ tge n untersuchung ist $\mathrm{zu}$ wiederholten Malen ausgeführt worden und hat im grossen ganzen stets dasselbe Resultat ergeben. Ein vollständiger Pneumothorax wurde erzielt mit einigen strangförmigen Adhärenzen nach oben 
und aussen. Im Oberlappen gegenüber der Befestigung der Adhärenzen liegt eine Kaverne, deren äussere Konturen etwas durch die Adhärenzen beeinflusst sind, indem sich diesen entsprechend eine schwache Vorwölbung der Oberfläche findet. Die Adhärenzen selbst erscheinen kompakt.

Bei der Sektion am 27. XI. fand sich immer noch ein linksseitiger Pneumothorax. Die Lunge war gut komprimiert ohne frische Tuberkulose und mit vier festen fibrösen Strängen, von der Dicke eines Daumens bis zu der eines Kleinfingers, an der Thoraxwand befestigt. Im Oberlappen gegenüber der Befestigung der Adhärenzen findet sich eine gut spanischnussgrosse Kaverne. In der anderen Lunge spärliche kleine Tuberkel. Im Darm zahlreiche tuberkulöse Geschwüre.

Bei einem genaueren Vergleich zwischen dem Röntgenbefund und dem Sektionsresultat ist folgendes von Interesse. Bei der Seltion wurde eine Adhärenz mehr gefunden als auf der Röntgenaufnahme zu sehen war. Nach meiner Auffassung war es gerade die dickste derselben, welche durch ihre Lage am weitesten nach hinten durch die Lunge verdeckt war und nicht auf der Röntgenplatte zum Vorschein kam. Das Bemerkenswerteste ist doch der Unterschied in der Dicke. Auf der Röntgenaufnahme scheinen die Adhärenzen in der Nähe der Lunge etwa $1-1^{1 / 2} \mathrm{~cm}$ breit $\mathrm{zu}$ sein. An den mikroskopischen Präparaten, von der Basis der Adhärenzen stammend, ist die dickste derselben 1,7-2 cm im Durchmesser. Die Adhärenz Nr. 2 misst $1,8 \times 1,2 \mathrm{~cm}$, die dritte und vierte $1 \times 1 \mathrm{~cm}$. Wo die Adhärenzen am schmalsten sind, scheint auf der Röntgenaufnahme der Durchmesser nur 2-3-4 $\mathrm{mm}$ zu sein, am Sektionspräparat ist der Durchmesser etwa $3 / 4 \mathrm{~cm}$. Ebenfalls kommt es mir vor, als ob die Adhärenzen in Wirklichkeit kürzer wären als auf der Röntgenaufnahme. Wie grosse Rolle hierbei Härtung und Schrumpfung spielen, kann ich nicht entscheiden. Auf der Röntgenaufnahme sieht man ferner die Kaverne sich bis an die Basis der Adhärenz,fortsetzen, möglicherweise mit einer flachen Ausbuchtung nach der Adhärenz, hin, aber die Adhärenzen selbst erscheinen kompakt. Bei Untersuchung des Präparats nach der Sektion findet man den sichtbaren Teil der Kaverne etwa von derselben Grösse und Ausdehnung wie auf der Röntgenaufnahme. Dagegen hat man in Schnitten durch die Adhärenz in der Nähe der Lunge inmitten derselben mehrere Nekrosen gefunden. Bei Sondierung gelangt man von denselben aus direkt in die Kaverne hinein. Sondiert man in entgegengesetzter Richtung, so gelangt man ein weiteres Stück in die Adhärenz hinein. In den beiden dicksten Adhärenzen war dies der Fall. In der einen konnte man am gehärteten Präparat die Nekrose etwa $11 / 2 \mathrm{~cm}$ weit verfolgen, in der anderen bis $1 \mathrm{~cm}$ von der Befestigung derselben an der Lunge, d. h. in der einen in nahezu der Hälffte, in der anderen in etwa $1 / 3$ ihrer Länge. In den zwei übrigen, welche ebenfalls nahe der Kaverne befestigt waren und an der Basis etwa $1 . \mathrm{cm}$ 
im Durchmesser massen, fanden sich keine Ausläufer. Die praktischen Konsequenzen hiervon liegen auf der Hand. Bei einer eventuellen Abbrennung bemerkt man wahrscheinlich nicht, dass man durch eine nekrotische Partie dringt. Vorläufig sieht alles hoffnungsverheissend aus; aber bei dem ersten Hustenstoss wird wahrscheinlich der nekrotische Pfropfen im Adhärenzstumpf in die Pleurahöhle hinausgeschleudert, und es erfolgt eine Infektion durch Tuberkelbazillen und vielleicht auch eine Sekundärinfektion durch Eiterbakterien aus der Kaverne. Die Folge wird in letzterem Falle ein Empyem mit Mischinfektion und freier Kommunikation zwischen der Kaverne und der Pleurahöhle, demnach ein Zustand mit äusserst schlechter Prognose. Forlanin is neun Fälle von spontanem Bersten von Kavernen in die Pleurahöhle, also ein völlig analoges Verhältnis, sind alle binnen kurzer Zeit tödlich verlaufen. Dieser Fall muss bei einer Abbrennung eintreffen, wenn die Kaverne, wie in den von Brauer, Sa u gman u. a. beschriebenen Fällen, einen Ausläufer bis in die Pleura parietalis entsendet. In solchen Fällen bedingt die Operation die ernsteste Komplikation, welcher man begegnen kann.

Es ist indessen einleuchtend, dass, wenn in diesem Falle die Abbrennung an der peripheren Hälfte der Adhärenzen ausgeführt worden wäre, eine Eröffnung der Kaverne hätte vermieden werden können. Es ist unmöglich zu sagen, wieviel Gewebe zwischen der Kaverne und der Abbrennungsstelle vorhanden sein muss, damit nicht nach einiger Zeit die Kaverne in die Pleura durchbrechen soll. Die Adhärenzen bestehen aus einem festen, fibrösen oder zirrhösen Gewebe, weshalb man Grund hat zu hoffen, dass recht kleine Bindegewebsbrücken ausreichend sein werden, um eine derartige Komplikation zu verhindern. Es scheint mir auch nicht ganz ausgeschlossen zu sein, dass eine Kaverne eine gewisse Tendenz hat, sich in einer strangförmigen Adhärenz bei Pneumothoraxbehandlung aktiv auszubreiten. Nach dieser Richtung zeigt sich jedoch gegen den tuberkulösen Prozess die geringste Widerstandskraft.

Auf jeden Fall steht fest, dass unter diesen Verhältnissen eine Operation gerade in denjenigen Fällen, in welchen dieselbe anscheinend den grössten Nutzen herbeiführen sollte, die ernstesten Komplikationen verursachen kann, ohne dass durch die Röntgenuntersuchung oder durch andere Methoden völlig sichere Aufschlüsse darüber zu gewinnen sind, wie diese Komplikation zu vermeiden ist.

Fasse ich das Resultat des obigen Vergleiches zusammen, so ergibt sich folgendes: In den Fällen, wo die Röntgenuntersuchung und die Thorakoskopie resp. die Sektion übereinstimmende Resultate ergeben haben, hat es sich im allgemeinen um nur eine Adhärenz 
gehandelt. Charakteristisch ist in diesen Fällen nicht nur das Aussehen der Adhärenz, sondern auch die Kontur der Lunge selbst. Sie ist spitzwinklig in einen Zapfen ausgezogen und mit einem dünneren oder dickeren Faden irgendwo an der Thoraxwand oder dem Zwerchfell befestigt. Dahingegen kann man nicht entscheiden, ob es sich um eine Membran handelt, die rechtwinklig geğen die Photographieebene steht. Dies kann möglicherweise durch eine Durchleuchtung von verschiedenen Seiten oder durch eine Schrägaufnahme entschieden werden, und dürfte auch keine so grosse Rolle spielen bei einer eventuellen Abbrennung. In allen Fällen, wo mehrere Adhärenzen vorhanden waren, ist die Lunge freilich etwas ausgebuchtet gewesen nach der Adhärenz hin, aber die Konturen sind mehr oder weniger rundlich oder uneben gewesen. Man erhält den Eindruck, dass eine Traktion an der Lunge in mehr als einer Richtung ausgeübt wird, ohne dass die Ursache nachgewiesen werden kann. Dieses Kennzeichen kann natürlich nicht von absoluter Gültigkeit sein, da grössere oder kleinere Infiltrationen in der Lunge leicht zu unregelmässigen Konturen Anlass geben. Handelt es sich indessen um strangförmige Adhärenzen nebst einer solchen, ungleichmässig konturierten Lunge, so muss man in bezug auf die Abbrennung vorsichtig sein, da eine viel grössere Zahl von Adhärenzen, als man berechnet, bei der Thorakoskopie entdeckt werden können. Schliesslich ist bemerkenswert, dass sowohl aus der Thorakoskopie als aus der Sektion hervorzugehen scheint, dass die Adhärenzen in Wirklichkeit oft dicker sind als sie auf der Röntgenplatte aussehen, was natürlich für eine eventuelle Abbrennung von einer gewissen $\mathrm{Be}$ deutung ist. Im Fall 8 war das Gegenteil der Fall. Dies ist mehr in Übereinstimmung damit, was man nach theoretischen Berechnungen zu erwarten hat. Die Erklärung für die ungleichen Resultate kann man möglicherweise in der Art und Weise finden, wie die Röntgenaufnahme gemacht wird. Wird ein hartes Rohr angewandt, muss die Adhärenz eine grössere Stärke erreichen, ehe sie einen Schatten ergibt, was zur Folge hat, dass dieselbe schmäler erscheint, als sie in Wirklichkeit ist.

Pathologisch-anatomische Untersuchungen tuberkulöser Lungen, die durch künstlichen Pneumothorax komprimiert gewesen sind, liegen in recht grosser Anzahl vor und sind ausgeführt von Graetz ${ }^{1}$, $\mathrm{Burckhardt}{ }^{2}$ ), $\mathrm{Warnecke}^{3}$ ), $\mathrm{Kistle}^{4}$ ) u. a. Im allgemeinen

1) Brauers Beiträge. Bd. 11.

2) Br a u er s Beiträge. Bd. 23.

3) Br a u ers Beiträge. Bd. 16.

4) B r a u ers Beiträge. Bd. 19 . 
sind die Resultate recht übereinstimmend. Man findet durchweg starke Bindegewebsschrumpfung mit mehr oder weniger umfangreichem Zugrundegehen von Lungenepithel, Gefässen und kleineren Bronchien.

In den Arbeiten, welche mir zugänglich gewesen sind, hat man eventuell vorfindlichen Adhärenzen keine besondere Aufmerksamkeit gewidmet. Es hat auch keine direkte Veranlassung hierzu vorgelegen, abgesehen von der makroskopischen Untersuchung der Beziehungen der Adhärenzen zu darunterliegenden Kavernen.

Für das hier in Rede stehende Verfahren ist es natürlich von grossem Interesse, den Gefässreichtum der Adhärenzen zu studieren. Besteht die Gefahr einer Blutung unmittelbar oder einige Zeit nach einer solchen Abbrennung? Diesbezüglich hat sich herausgestellt, dass in den Adhärenzen interessante Gefässveränderungen nachzuweisen sind, die sowohl für die Abbrennung als auch für die Erklärung des spontanen Reissens dünner Adhärenzen während der Pneumothoraxbehandlung von Bedeutung sind.

An den zwei zuvor referierten Sektionsfällen, wo ich das Resultat der Röntgenuntersuchung mit dem Sektionsbefund verglichen habe, habe ich die Adhärenzen mikroskopisch untersucht, wie auch in drei anderen Fällen, wo die Röntgenuntersuchung von geringerem Interesse war. Insgesamt sind 13 Adhärenzen in Fällen, wo längere oder kürzere Zeit, gewöhnlich etwa 1 Jahr lang, ein Pneumothorax vorhanden gewesen war, untersucht worden. Der Kontrolle halber habe ich in sämtlichen Fällen Teile der komprimierten Lunge in den betreffenden Fällen, wie auch Adhärenzen und Pleuraschwarten, von nicht pneumothoraxbehandelten Lungen herrührend, untersucht.

Die Organe sind in 4\% Formalin gehärtet worden; die Färbungen sind Hämatoxylin-Eosin, van Gieson und Fränkels Elastinfärbung gewesen.

Die mikroskopische Untersuchung von Pleuraschwarten unter gewöhnlichen Verhältnissen hat nichts von Interesse ergeben über das hinaus, was zuvor bekannt war. Es ist ein mehr oder weniger gefässreiches Granulationsgewebe ohne irgendwelche Gefässveränderungen gewesen.

Wo kein Pneumothorax vorgelegen hat, sind die strangförmigen Adhärenzen locker gebaut mit spärlichen Bindegewebsstreifen und recht grossen Variationen in bezug auf den Gefässreichtum. In der Mehrzahl der Adhärenzen sind die Gefässe von gewöhnlichem Aussehen. Untersucht man dahingegen lange, fadenförmige Adhärenzen, die bei Lebzeiten einer mehr oder weniger starken Dehnung ausgesetzt gewesen sind, so findet man doch zuweilen Gefässverände- 
rungen von ähnlichem Aussehen wie in den Adhärenzen in pneumothoraxbehandelten Fällen. Nirgends deutliche Reste von Lungengewebe in den wenigen Fällen, die ich untersucht habe.

In den hier untersuchten Sektionsfällen hat die komprimierte Lunge bei mikroskopischer Untersuchung dieselben Veränderungen gezeigt, welche frühere Verfasser beschrieben haben: starke Bindegewebsinduration, hier und da Zugrundegehen von Gefässen und kleinen Bronchien. In diesen Fällen sind die Gefässveränderungen im ganzen genommen spärlich. Zumeist scheint eine Verdickung der Adventitia und des perivaskulären Bindegewebes vorzukommen.

Das grösste Interesse bieten die Adhärenzen dar. Schon makroskopisch verhalten sie sich ganz anders als die zuvor beschriebenen. Es sind kompakte, harte Stränge von oft grosser Festigkeit.

Der allgemeine mikroskopische Bau ist auch ein ganz anderer. In den ersteren Adhärenzen findet sich kein Lungengewebe, in den letzteren finden sich mehr oder weniger erhebliche Reste von solchem Gewebe. Die ersteren sind locker mit spärlichen Bindegewebsstreifen, die letzteren fest, hauptsächlich aus fibrösem Gewebe aufgebaut. In den letzteren finden sich überdies Gefässveränderungen von einem gnaz eigentümlichen Aussehen, wie sie meines Wissens nicht zuvor beschrieben worden sind.

Da ich durch diese Untersuchung vor allem die zweckmässigste Stelle für eine Abbrennung bestimmen wollte, habe ich Querschnitte der Adhärenzen an drei verschiedenen Stellen, nämlich nahe der Lunge, an der schmalsten Stelle der Adhärenz und nahe der Pleura parietalis untersucht.

Nahe der Lunge $(1 / 2-1 \mathrm{~cm})$ findet man auf dem Querschnitt stets Lungengewebe in erheblicher Menge mit seinem Epithel, seinem netzförmigen interstitiellen Gewebe und nicht selten Kohlenpigment. Das Lungengewebe bildet kleinere Läppchen, durch Bindegewebsstreifen getrennt. Die Ähnlichkeit mit dem Aussehen der komprimierten Lunge im übrigen ist recht gross. An gewissen Stellen findet man Alveolarepithel, bald von gewöhnlichem Aussehen, bald von sog. fötalem Typus. Ziemlich selten findet man Hohlräume mit hohem, zylindrischem Epithel bekleidet, ohne Zweifel Reste der äussersteu Bronchialverzweigungen. Dies ist, was vom Lungenparenchym übrig ist. Was das Stützgewebe betrifft, findet man wie erwähnt eine höchst bedeutende Vermehrung der Bindegewebselemente; dicke Bindegewebsstreifen durchziehen hier und da die Adhärenz, an der Oberfläche hat man gewöhnlich eine mehr oder weniger dicke Bindegewebsschicht nach vorausgegangener organisierter Pleu- 
ritis. Hier liegen die Bindegewebsstreifen in parallelen Bündeln mit ziemlich spärlichen und unbedeutenden Gefässen.

Schon in diesen Präparaten ziehen die Gefässe eine gewisse Aufmerksamkeit auf sich, indem man hier und da Gefässe mit ausserordentlich verdickter Wand und verengertem Lumen antrifft. Die Längsmuskelschicht ist es, welche stark hypertrophisch ist.

Hier und da liegen Rundzellenherde, Nekrosen und Riesenzellen von L a ngerhans schem Typus. Die Nekrosen sind meistens von recht zirrhösem Bindegewebe umgeben, auf eine Einkapselung des Herdes deutend.

Bei Fränkels Elastinfärbung findet man das elastische Lungengewebe, die Felder zwischen den kompakten Bindegewebsstreifen einnehmend, ein ausserordentlich hübsches Netzwerk bildend. In den Gefässwänden finden sich die elastischen Membranen oft in mehreren Schichten.

Ein Querschnitt durch eine Adhärenz an ihrer schmalsten Stelle gibt ein wesentlich anderes Bild. Waș zunächst frappiert, ist der nahezu totale Mangel an epithelialen Lungenelementen. Nirgends sieht man Alveolarepithel in irgend einer Form. An einigen Steller. sieht man ein zellreicheres, lockereres Gewebe. Zuweilen sind hier und da zerstreute Kohlenpigmentflecke zu sehen. An elastingefärbten Schnitten wiederum findet man überall, wo das Gewebe etwas lockerer ist, die für Lungengewebe charakteristische Anhäufung von elastischem Gewebe in dichten zierlichen Locken. Auf Längsschnitten sieht man, dass die elastischen Fäden deutlich in der Länge aus. gezogen sind und in parallelen Reihen beinahe wie Bindegewebsbalken liegen. Speziell nahe der Befestigung der Adhärenz an der Thoraxwand ist die längsverlaufende Richtung der Fäden markant. $\mathrm{Zu}$ ihrem wesentlichsten Teil besteht die Adhärenz hier aus festem, fibrösem, ziemlich zellarmem Bindegewebe mit längslaufenden Fasern von fast überall demselben Aussehen. Das grösste Interesse bieten die Gefässe. Sie zeigen ausserordentlich charakteristische Veränderungen, die meines Wissens nicht zuvor beschrieben worden sind, auch nicht in der komprimierten Lunge. Alle Gefässe mit wenigen Ausnahmen haben eine stark verdickte Wand, wodureh das Lumen verengert wird oder gänzlich verschwindet. $O b$ es vorzugsweise Arterien oder Venen sind, welche diese Veränderung aufweisen, lässt sich nicht mit Sicherheit entscheiden. Die Struktur der betreffenden Gefässe scheint am meisten derjenigen der Arterien zu, gleichen.

Es ist vor allem die längsverlaufende Muskulatur, welche häufig verdickt erscheint. Sehr häufig ist in die Muskularis ein feines Netzwerk von Bindegewebsfäden eingesprengt. Zuweilen sieht man 
eine gewisse Schichtung, so dass Muskelschichten mit Bindegewebsschichten 3-4 mal abwechseln. Im Bindegewebe findet man zuweilen Rundzellen eingestrent, auf einen entzündlichen Prozess deutend (Fig. 18). Von der Intima in diesen Gefässen ist es schwer, eine klare Vorstellung zu gewinnen. An elastingefärbten Schnitten erscheinen die elastischen Membranen von sehr wechselndem Ausselhen. Zuweilen hat die Elastika ein normales Aussehen, zuweilen ist sie, besonders in den Gefässen, welche Sitz endarteritischer Prozesse sind, in zahlreichen konzentrischen Schichten angeordnet. 1)as Gesamturteil über das Vorkommen und die Entwickelung des clastischen Gewebes in den Gefässen wird daher, dass auch dieses hyper-

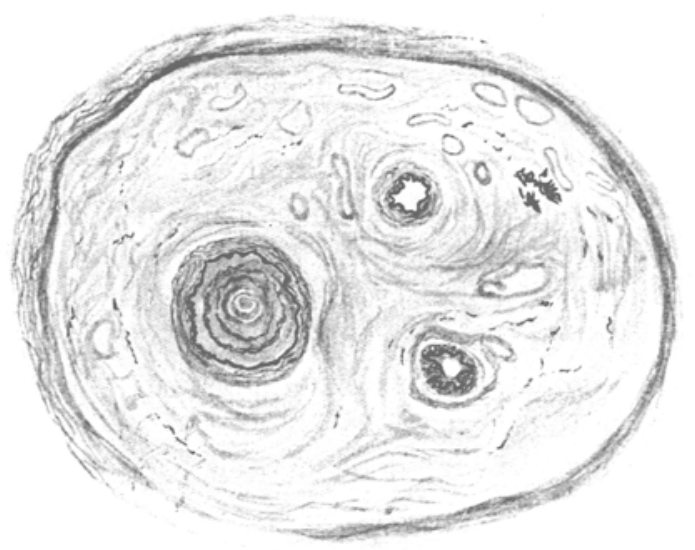

trophisch ist, wenn auch nicht in demselben Grade wie die längsvcrlaufende Muskulatur (Textfigur).

Schnitte nahe der Pleura parietalis geben wiederum ein anderes Bild. Hier dominieren weniger kompakte, mässig zellreiche Bindegewebsbündel. Von den epithelialen Elementen der Lunge ist meistens keine Spur zu entdecken. Bei Elastinfärbung findet man in den Gefässwänden die Elastika von gewöhnlichem Aussehen, aber in den übrigen Geweben ist sie ausserordentlich spärlich. Nur in der Nähe der Gefässe kann man selten kleinere Streifen von elastischem Gewebe eingesprengt finden. Eine für Alveolen charakteristische Anordnung der elastischen Fäden habe ich nicht wahrgenommen. Die Gefässe nahe der Pleura sind vor allem spärlicher als näher der Lunge. Ferner sind die Wände derselben verdickt, aber kaum in derselben Weise wie zuvor. In manchen Gefässen findet sich eine Hypertrophie der Muskularis in derselben Weise, wie zuvor beschrieben, aber in zahlreichen Gefässen ist die Media von gewöhn- 
licher Dicke, während das umgebende Bindegewebe in konzentrischen Schichten angeordnet ist, auf eine Verdickung der Adventitia deutend.

Die hier gegebene Beschreibung gilt für das Aussehen der Adhärenzen im allgemeinen. Die Variationen, die ich beobachtet habe, sind recht klein. Bei dicken Adhärenzen sieht man das Lungengewebe sich weiter hinaus auf die parietale Pleura zu fortsetzen, die eigentümlichen Gefässveränderungen sind dann weniger markant.

Eine Ausnahme hiervon habe ich in einer gut zentimeterdicken Adhärenz gefunden, wo ich nur sehr spärliches elastisches Gewebe angetroffen habe, ja so wenig, dass man hiernach kaum zu entscheiden wagt, ob hier wirklich Lungengewebe in die Adhärenz hineingezogen worden ist. Andererseits habe ich in fadendünnen Adhärenzen aus dem Fall 1 in etwa $2 \mathrm{~cm}$ Entfernung von der Lungenoberfläche elastisches Gewebe von solchem Aussehen gefunden, dass man mit grosser Wahrscheinlichkeit annehmen muss, dass Reste von Lungengewebe vorgelegen haben (Textfi war). Reste von Lungenepithel habe ich jedoch nicht angetroffen.

Die grössten Variationen im Aussehen bieten die pleuritischen Beläge an der Oberfläche der Adhärenzen. In einigen Fällen ist der Belag ganz dünn und ohne Bedeutung; in anderen bildet er eine $1 / 2-1 \mathrm{~cm}$ dicke Schicht von zirkulär angeordneten Bindegewebsbündeln, welche ausserordentlich arm an Gefässen und Zellen sind. An gewissen strangförmigen Adhärenzen ist die ursprüngliche Adhärenz nur ein dünner Faden, während der Hauptteil aus Granulationsgewebe besteht. Zuweilen sieht man in denselben Rundzellen infiltrationen mit Langerhan s schen Riesenzellen.

Ohne Zweifel entstehen diese Auflagerungen durch die bei der' Pneumothoraxbehandlung so gewöhnlichen Pleuritiden. Ihre Bedeutung, wenn sie auch für die hier behandelten Fragen nicht so gross ist, ist zweifacher Art. Sind die Beläge so gross, dass sie eine Dicke von $1 / 2-1 \mathrm{~cm}$ erreichen, so müssen sie die Abbrennung einer derartigen Adhärenz erschweren. Der beste Zeitpunkt für diese Operation wird daher vor dem Auftreten der pleuritischen Exsudate sein. Ferner kann man die Schlussfolgerung ziehen, dass nach dem Erscheinen des Exsudates die strangförmigen Adhärenzen durch diese weiteren Auflagerungen von Bindegewebe verstärkt werden. Jedenfalls muss die Möglichkeit eines spontanen Reissens derartiger Adhärenzen durch hohen Druck erheblich geringer werden.

Dass die Gefässveränderungen das hier beschriebene eigentümliche Aussehen mit einer enormen Hypertrophie der längsverlaufenden Muskulatur und in gewissem Grade auch der Elastika des Gefässes 
annehmen, dürfte mutmasslich von rein mechanischen Verhältnissen herrühren. Es ist eine starke Beanspruchung, welcher diese Adhärenzen ausgesetzt sind, schon wenn es nur einfache Bänder sind, die mehr oder weniger das Gewicht der Lunge tragen. Eine noch grössere Dehnung entsteht, wenn man durch Überdruck versuchen will, eine derartige Adhärenz zum Reissen zu bringen. Als eine Reaktion hierauf kann man die geschilderte Hypertrophie des muskulären und des elastischen Gewebes auffassen.

Aus diesen pathologisch-anatomischen Untersuchungen gehen mehrere wichtige Tatsachen hervor, die für die Ausführung endopleuraler Eingriffe von Bedeutung sind.

Erstens dürfte es sicher sein, dass die Adhärenzen in der Mehrzahl der Fälle zum grossen Teil aus dem Lungengewebe selbst gebildet werden. Nahe der Lunge findet man alle in der Lunge vorkommenden Gewebsbestandteile. Weiter nach aussen verschwinden die epithelialen Elemente, während das Stützgewebe, vor allem das elastische Gewebe, recht weit hinaus, in den dickeren häufig bis zur Pleura parietalis verfolgt werden kann. Hierdurch erhält man eine einwandfreie Erklärung, weshalb Kavernen Ausläufer in Adhärenzen haben können, wie Brau er, $\mathrm{Sa} \mathrm{u} \mathrm{g} \mathrm{man} \mathrm{u.} \mathrm{a.} \mathrm{beschrieben}$ haben.

Ferner ist es klar, dass man in den Adhärenzen die gleiche Menge und Grösse der Gefässe zu erwarten hat wie in den peripheren Teilen der Lunge. Mächtige Venen, wie Forlan in i beschrieben, habe ich in diesen Fällen nicht beobachtet, obwohl ich darum nicht das Vorkommen derselben in Abrede stelle.

Hierzu kommen diese eigentümlichen Gefässveränderungen, wodurch Gefässe in recht grossem Umfang zugrunde gehen unter gleichzeitiger Hypertrophie der längsverlaufenden Muskulatur und des elastischen Gewebes. Zweifelsohne spielt dies eine Rolle beim spontanen Reissen strangförmiger Adhärenzen bei hohem Druck in der Pleurahöhle. In ganz entgegengesetzter Richtung wirken die pleuritischen Beläge, die als Verstärkung dienen. Man muss hieraus folgern, dass nach dem Erscheinen des Exsudates sich nicht nur die Möglichkeiten cines spontanen Reissens von Adhärenzen verringern, sondern auch das Abbrennen derselben erschwert wird.

Aus dem Obigen ergeben sich meines Erachtens recht gute Anhaltspunkte sowohl in bezug auf den Zeitpunkt als auf denjenigen Ort der Adhärenz, wo die Abbrennung vorzunehmen ist. Der beste Zeitpunkt muss sein, sobald die Lunge in möglichstem Grade komprimiert ist, und bevor ein pleuritisches Exsudat aufgetreten ist. Dio beste Stelle muss so nahe der Brustwand wie möglich sein. Hier 
ist der Gefässreichtum und die Gefahr auf einen Ausläufer einer Kaverne zu stossen am geringsten.

Die letztere Komplikation, deren verhängnisvolle Folgen ich vorher besprochen habe, will ich eingehender diskutieren. Die Natur derselben ist ja derart, dass sie die Berechtigung der Methode ernstlich bedroht. Andererseits zeigen die hier beschriebenen Fälle 3, 7 und 9, dass, wenn es gelingt, eine derartige Adhärenz zu beseitigen, man das glänzendste Resultat erzielen kann. Gegenwärtig besitzen wir keine andere chirurgische Methode, durch welche man so einfach und in so schonender Weise eine derartige Adhärenz beseitigen kann. Demnach diє grössten Vorteile wenn es gelingt, die ernstesten Folgen im entgegengesetzten Falle. Die Extreme berühren sich. Es müssen daher die grössten Anstrengungen gemacht werden, um diese gefährliche Komplikation zu vermeiden. Zuerst muss man $\mathrm{zu}$ erforschen suchen, wie oft Kavernen derartige Ausläufer entsenden. Die ersten Mitteilungen rühren von $\mathrm{S}$ a u g man her, welcher über ein en Fall berichtet, wo man bei der Operation einen derartigen Ausläufer fand. Sodann wird hier und da in den Publikationen verschiedener Verfasser erwähnt, dass derartige Ausläufer vorkommen. Aber eine Untersuchung darüber, wie oft dies der Fall ist, gibt es nicht. Ob es Regel oder Ausnahme ist, weiss man nicht. Ebensowenig hat man diskutiert. eine wie grosse Rolle die Dicke der Adhärenz spielt. Für mich steht die Sache so, dass man die für die Methode ungünstigen Fälle erwähnt hat, aber nicht die übrigen.

In dem Aufsatz von mir und Tideströ m findet sich erwähnt, dass Ausläufer von Kavernen vermutlich nicht Regel sind. Noch hat die Erfahrung dies nicht widerlegt. Im Fall 3, wo Abbrennung erfolgt ist, kann kein Ausläufer vorhanden gewesen sein, wenigstens nicht so weit hinaus wie an der Abbrennungsstelle. In den zwei Sektionsfällen fehlen Ausläufer in dem einen gänzlich, in dem anderen finder sich solche, welche das innerste Drittel oder die Hälfte der Länge der dicksten Adhärenzen einnehmen. In den dünnsten, die jedoch an der Lunge mehr als $1 \mathrm{~cm}$ im Durchmesser massen, fand sich kein Ausläufer. Eine Abbrennung nahe der Pleura parietalis würde in diesem Falle meines Erachtens die betreffende Kaverne nicht geöffnet haben.

In diessem Falle tritt eine andere wichtige Sache zutage, nämlich, dass diesc Ausläufer mit Detritus gefüllt sein können, welchenfalls die Röntgenuntersuchung in bezug auf die Diagnose der Ausläufer vollständig versagt.

Ferner wurden die Ausläufer in den dicken Adhärenzen gefunden, nicht in dünnen, und dies lenkt den Gedanken darauf, dass 
die Dicke vielleicht eine wesentliche Rolle spielt. Nach meiner Meinung ist die Wahrscheinlichkeit des Vorhandenseins eines Ausläufers. geringer, je dünner die Adhärenz ist. Weiter als zu diesem allgemeinen Ausspruch kommt man jedoch nicht, da man noch keine bestimmte untere Grenze angeben kann, unterhalb welcher Ausläufer nicht mehr gefunden werden oder zu erwarten sind. Auf Grund der Ungewissheit speziell in letzterer Hinsicht kann man nur versuchsweise Indikationen für die Anwendung der Methode aufstellen.

Strangförmige Adhärenzen ohne angrenzende Kaverne, welche auf die eine oder andere Art die Kompression der Lunge verhindern, können stets ohne nennenswerte Gefahr Gegenstand der in Rede stehenden Operation werden. Strangförmige Adhärenzen über Kavernen erfordern eine sehr sorgfältige Erwägung mit Rücksicht auf ihre Dicke, auf die Lage der Kaverne, ob man wagen kann, eine Abbrennung zu machen. Nur bei sehr dünnen Adhärenzen ist die Gefahr des Vorhandenseins eines Ausläufers der Kaverne sehr gering.

Von der Anwendbarkeit der Methode bei ausgebreiteten Verwachsungen hat man keine Erfahrung. Möglich ist, wie Hervé gezeigt hat, dass man durch wiederholtes Abbrennen in mehreren Sitzungen nach und nach auch breite Adhärenzen lösen kann.

Zum Schluss will ich einen Vergleich zwischen der von mir verwendeten Technik und den von Hervé und Jacobsson in Vorschlag gebrachten Veränderungen mit Abbrennung unter der Leitung der Röntgendurchleuchtung aufstellen. Der Nachteil meiner Methode ist, dass man vorerst eine ganz neue Untersuchungsmethode, die Thorakoskopie, erlernen muss, und dass wahrscheinlich recht grosse Übung erforderlich ist, bevor man einen Galvanokauter an der Hand des Thorakoskops manövrieren kann.

Mir scheint jedoch, als ob den Methoden von Hervé und Jacobsson noch grössere Nachteile anhaften. Hier manövriert man an der Hand von Schattenbildern auf dem Röntgenschirm, also ganz diffusen Bildern. Ferner geht aus meinen Untersuchungen hervor, dass viele Adhärenzen, und vielleicht gerade diejenigen, welche das grösste Hindernis darstellen, schlechtweg nicht zu entdecken sind. Ferner kann man, wenn etwa grössere Gefässe in den Adhärenzen vorkommen sollten, dies weder vor noch während der $\mathrm{Ab}$ brennung entdecken.

Bei einer Abbrennung unter der Leitung des Thorakoskops ist vielleicht sowohl die Orientierung als auch die Führung des Galvanokauters schwierig, aber man siehtalles, was mantut. Finden sich grosse Gefässe in den Adhärenzen, was mir bisher noch nicht 
passiert ist, so kann man dies wahrscheinlich im voraus entdecken und das Abbrennen inhibieren. Jedenfalls bekommt man sogleich zu wissen, ob eine Blutung eingetreten ist, und kann sofort gegen dieselbe einschreiten. Fall 8 zeigt die Bedeutung hiervon, da ich hier durch Kaustik eine wenn auch unbedeutende Blutung stillte. Man kann auch während der Thorakoskopie besser die Stelle für den Eingriff an der Adhärenz selbst wählen, was nicht ohne Bedeutung ist.

Hervé hat gegen die Thorakoskopie angeführt, dass sie ein zu kleines Gesichtsfeld gewährt. Dies muss darauf beruhen, dass er sich nicht mit der Technik der Thorakoskopie vertraut gemacht hat. Meiner Erfahrung gemäss hat der geringe Umfang des Gesichtsfeldes niemals irgendwelche Schwierigkeiten bereitet, diese liegen vielmehr, wie erwähnt, in der Orientierung in der Pleurahöhle und dem Manövrieren des Galvanokauters.

Schliesslich hat Jacobsson hervorgehoben, dass bei der Abbrennung nach seiner Methode nur e in e Punktionsöffnung erforder lich ist, und dass sie daher für den Patienten weniger angreifend ist. Durch Anwendung von Novokainanästhesie wird die ganze Operation schmerzlos ausgeführt, und es dürfte daher keine Rolle spielen, $o b$ eine oder zwei Punktionen gemacht werden.

\section{Figurenerklärung.}

Figg. 1, 2, 3 gehören dem Falle 3, siehe S. 4 u. 5, Figg. 4, 5, 6 " " $\quad$,,$\quad$ S. 6 u. 7, Figg. 7, $8 \quad " \quad, \quad$ " $\quad$, $\quad$ " S. 9 u. 10, Figg. 9, 10,11 $\quad " \quad$ " $\quad " \quad 7, \quad$ S. 11 u. 12, Figg. 12,13,14,15 " $\quad " \quad$ " $\quad 8, \quad$, S. 14, 15 u. 16, Figg. 16,17 $" \quad " \quad 9, \quad$ S. 17 u. 18 an.

Fig. 18 mikroskopisches Bild strangförmiger Adhärenz, siehe S. 30. 


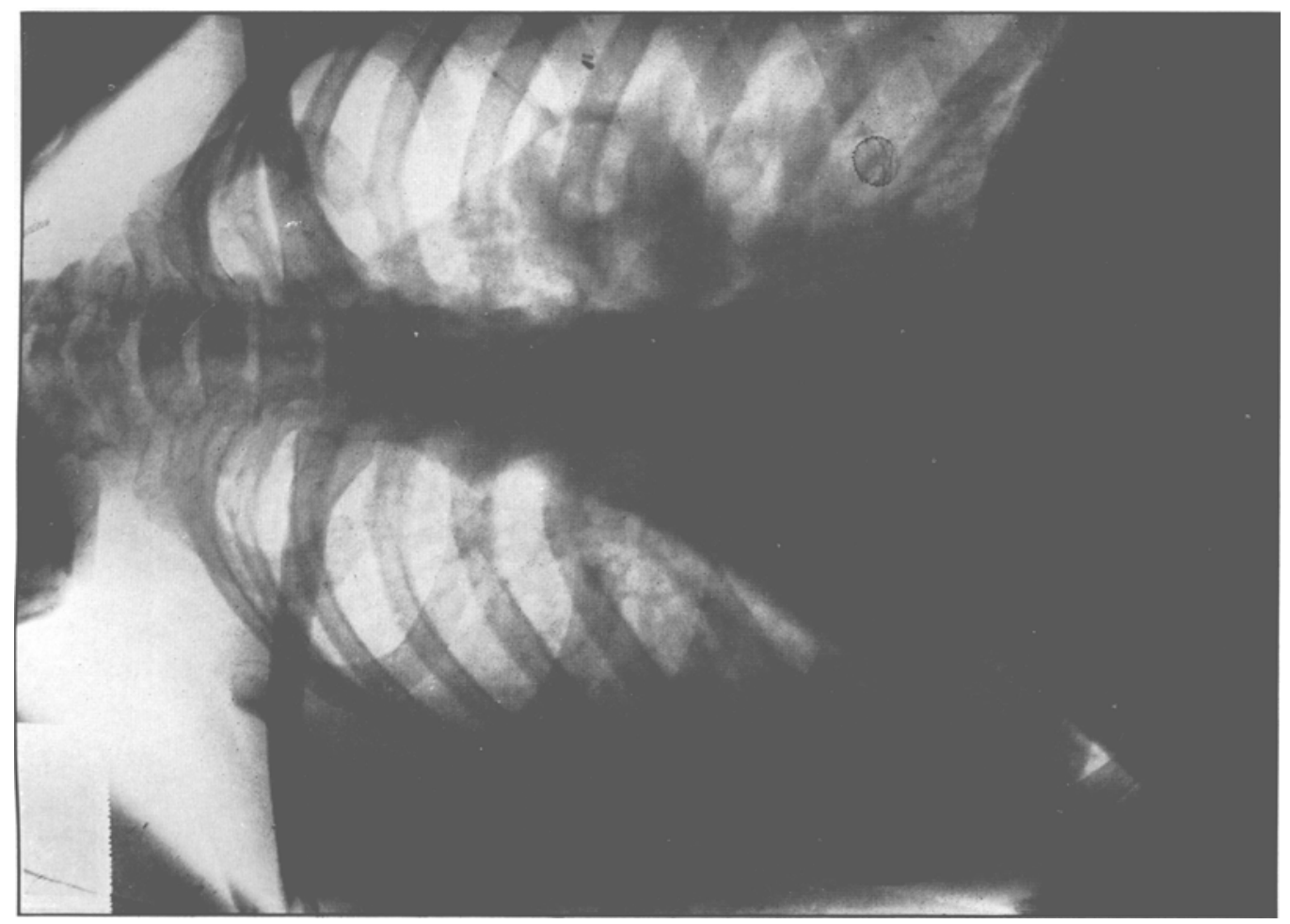

$\dot{+}$

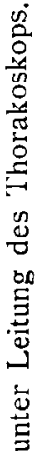

$\Xi$

.

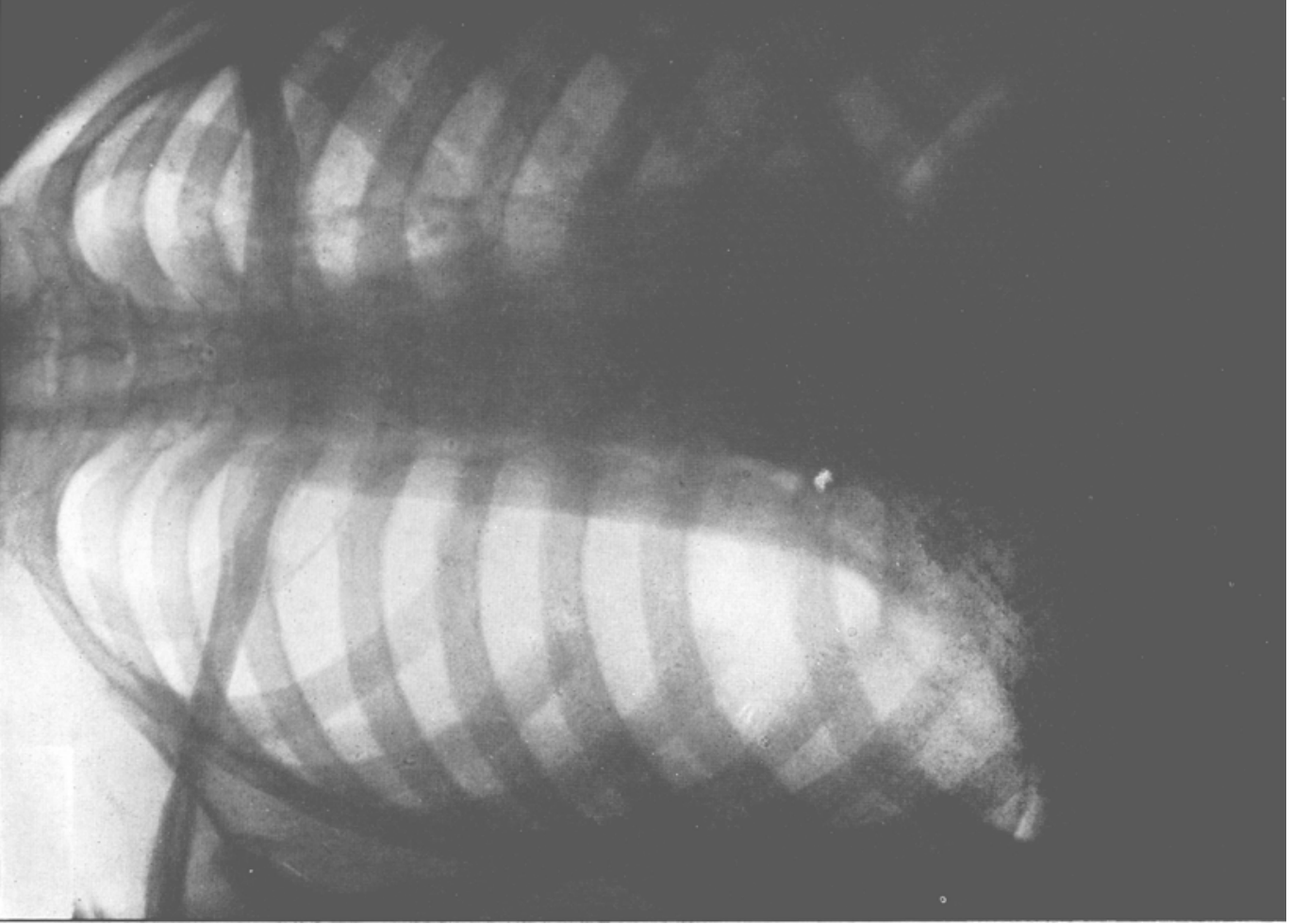

อั

$\stackrel{0}{\pi}$

壳

응 3

国

जิ

c)

:

0

$\stackrel{\leftrightarrow}{\rightarrow} \stackrel{0}{\longrightarrow}$

si

I

. 


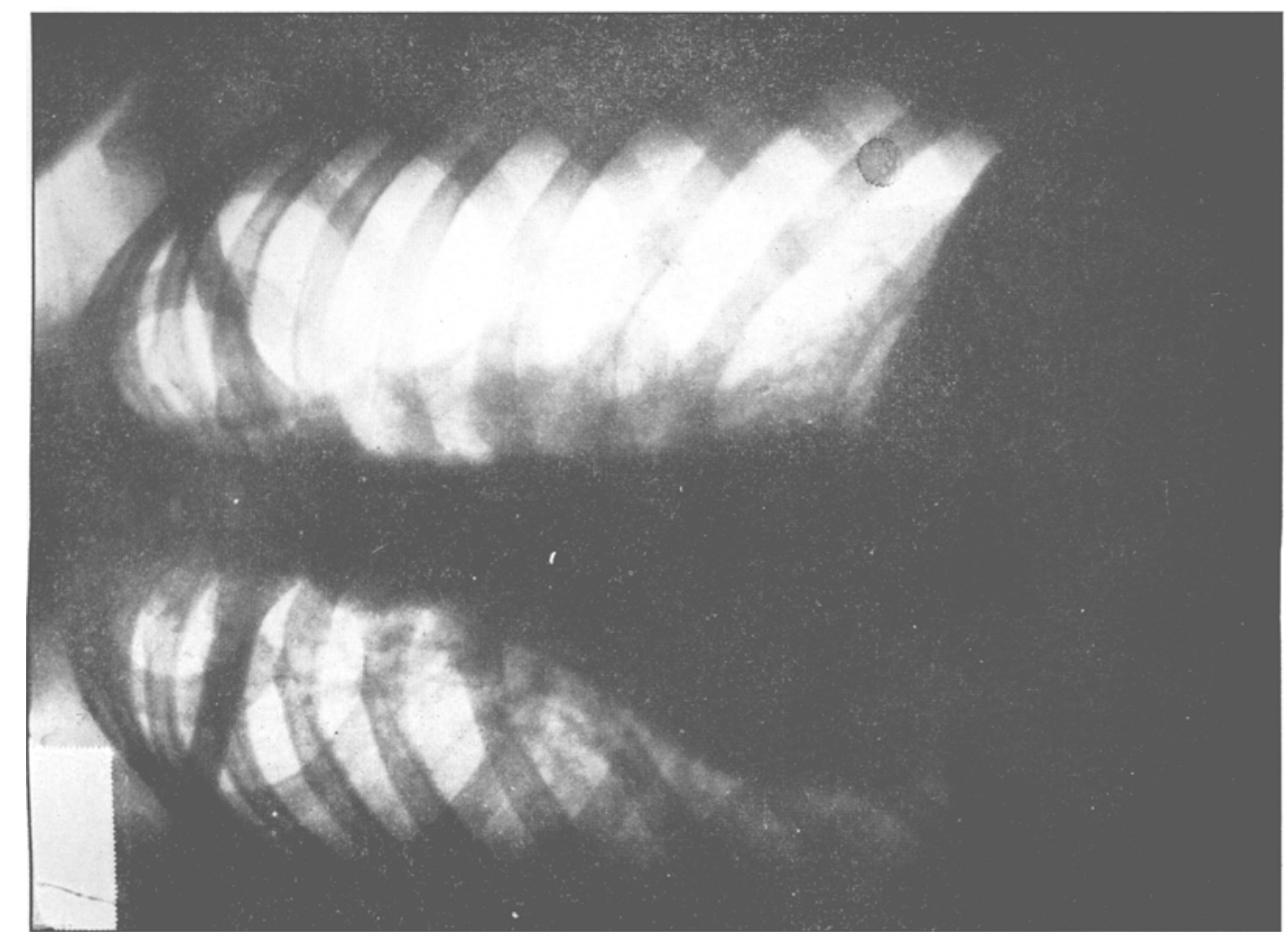

$\dot{0}$

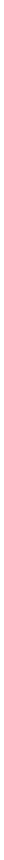




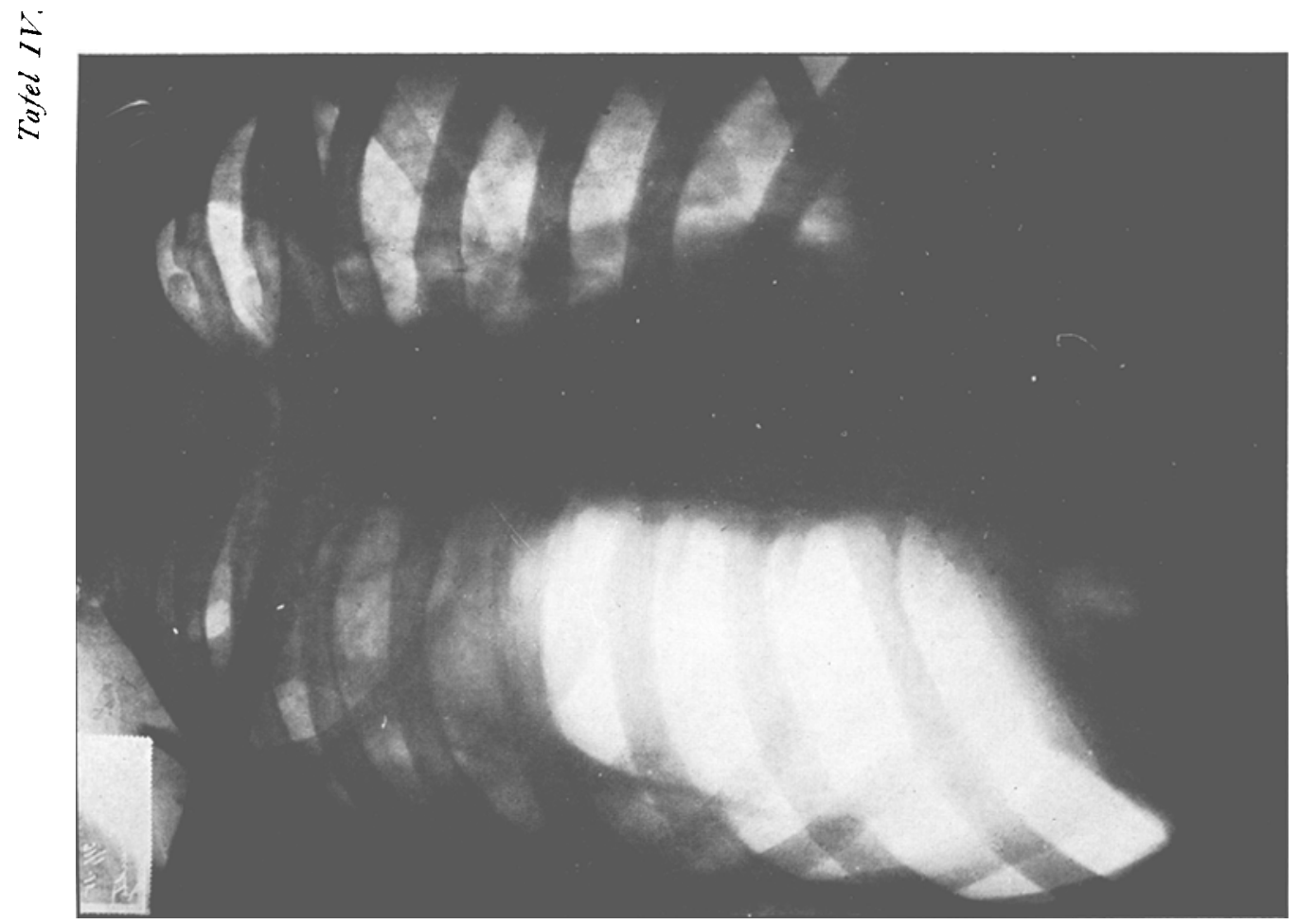

$\dot{0}$

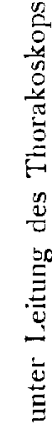



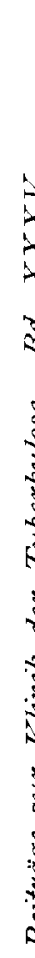

(2)

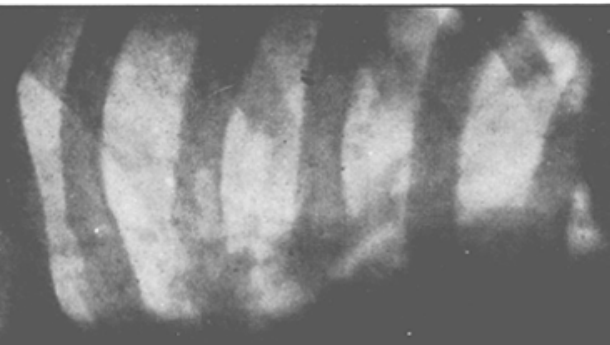




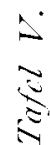

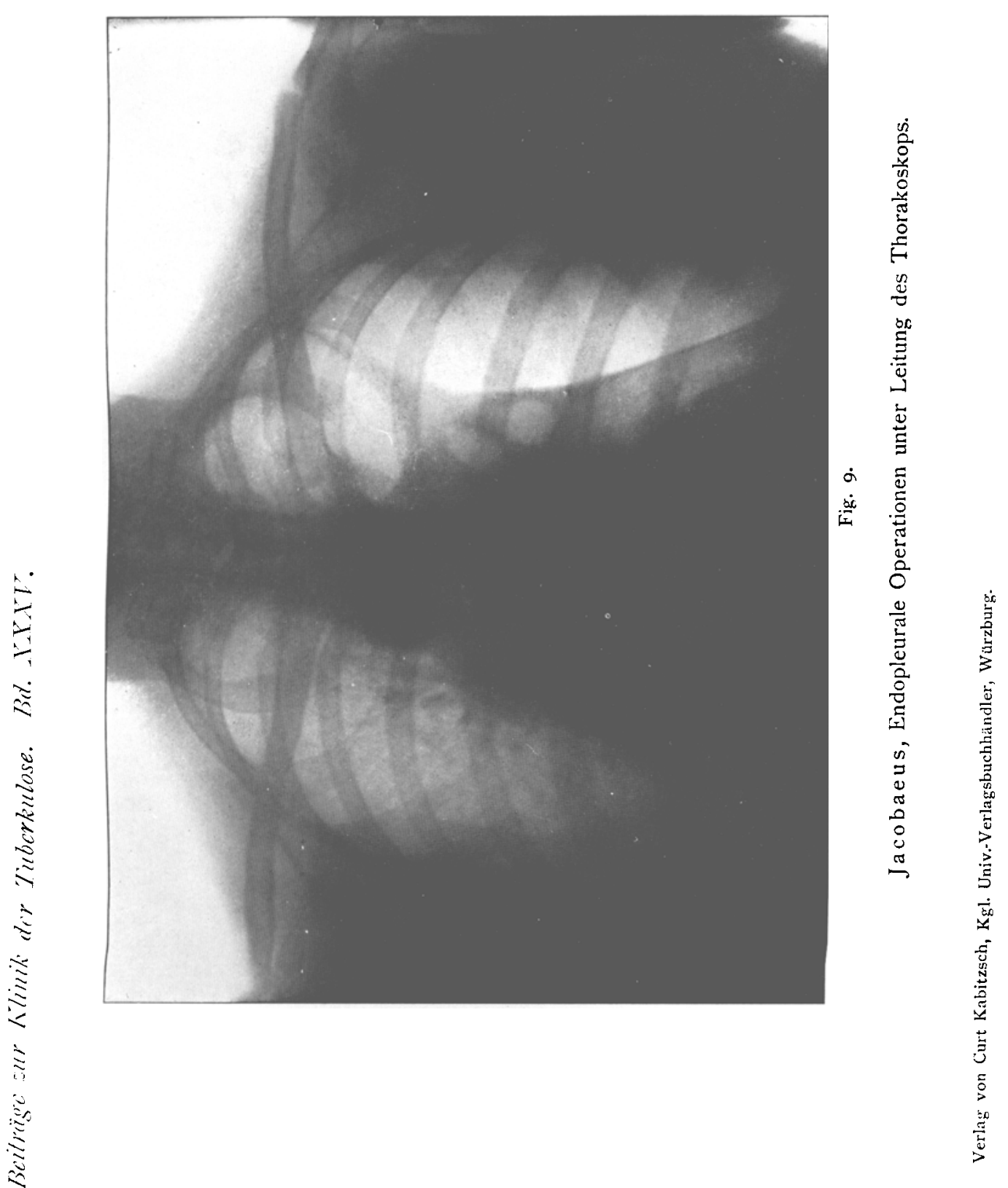


$\sum^{2}$

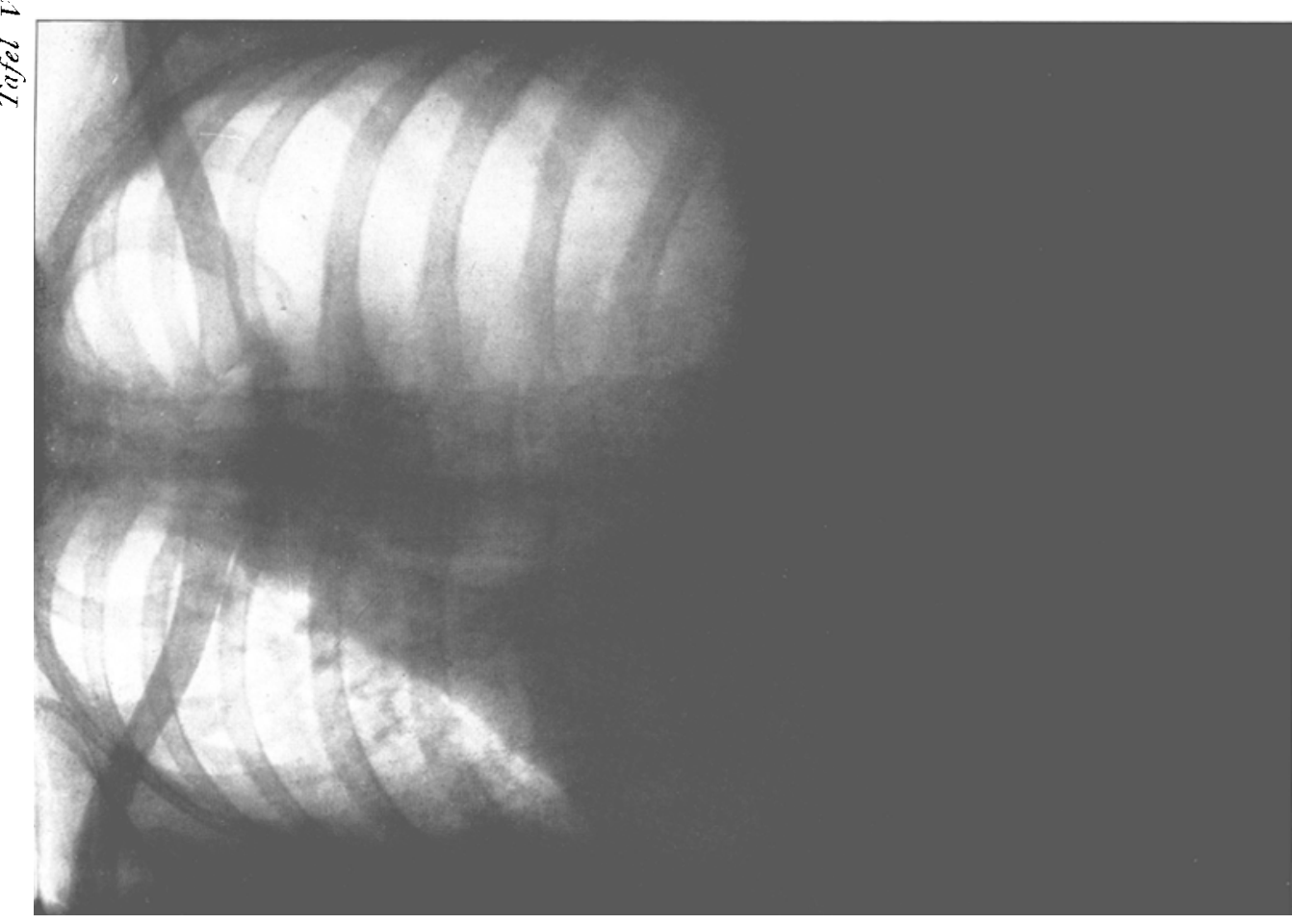

$\dot{4}$

in

过

芯

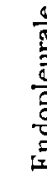

䨐

章

v

๘

응

过 $\dot{0}$

$\dot{0}$ :

政 


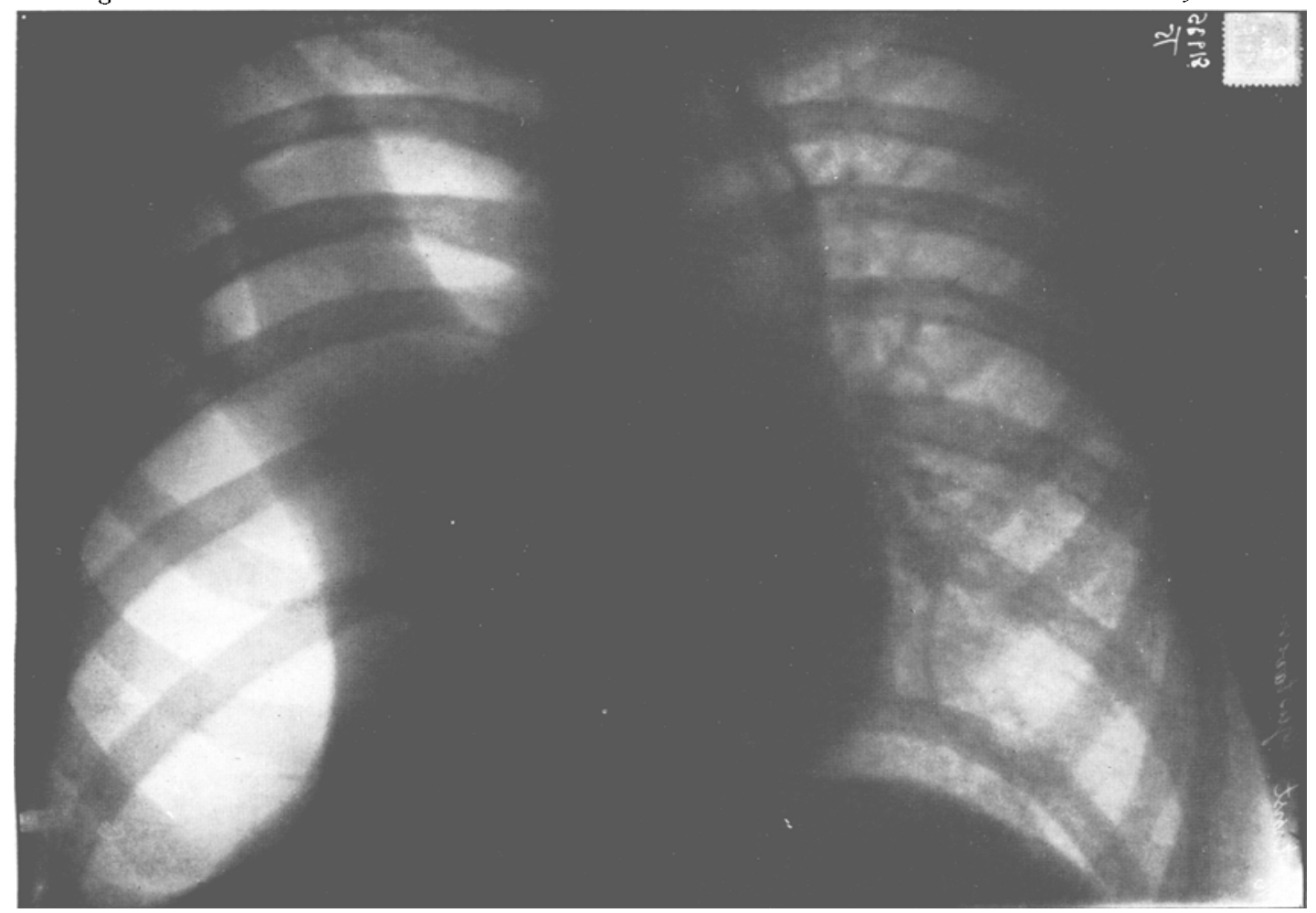

Fig. I2.

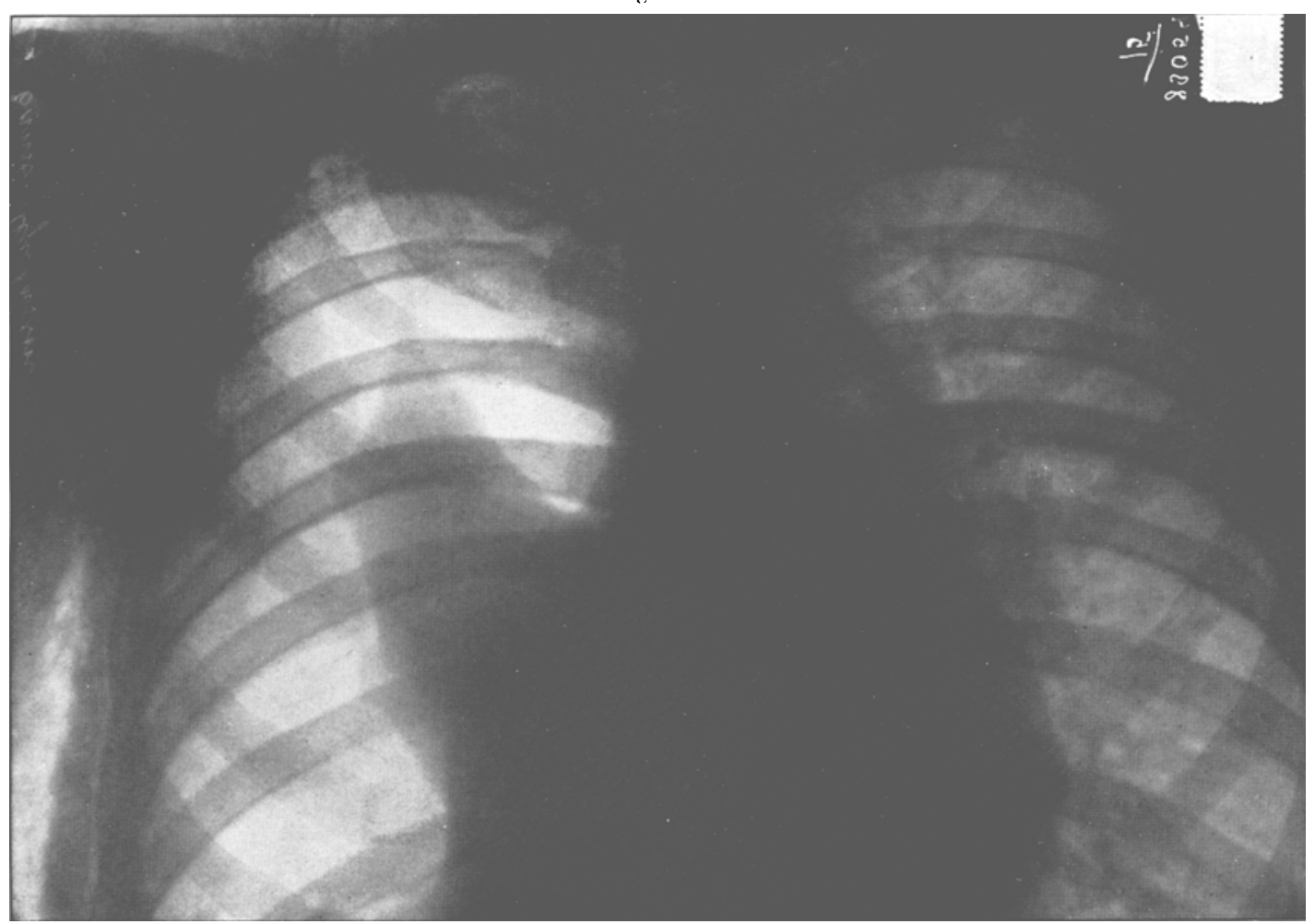

Fig. 13 .

Jacobaeus, Endopleurale Operationen unter Leitung des Thorakoskops. Verlagr von Curt Kabitzsch, Kgrl. Univ.-Verlagsbuchhündler, Würzburg. 
iträge zur Klinik der Tuberkulose. $B d . X X X V$.

Tafel VIII.
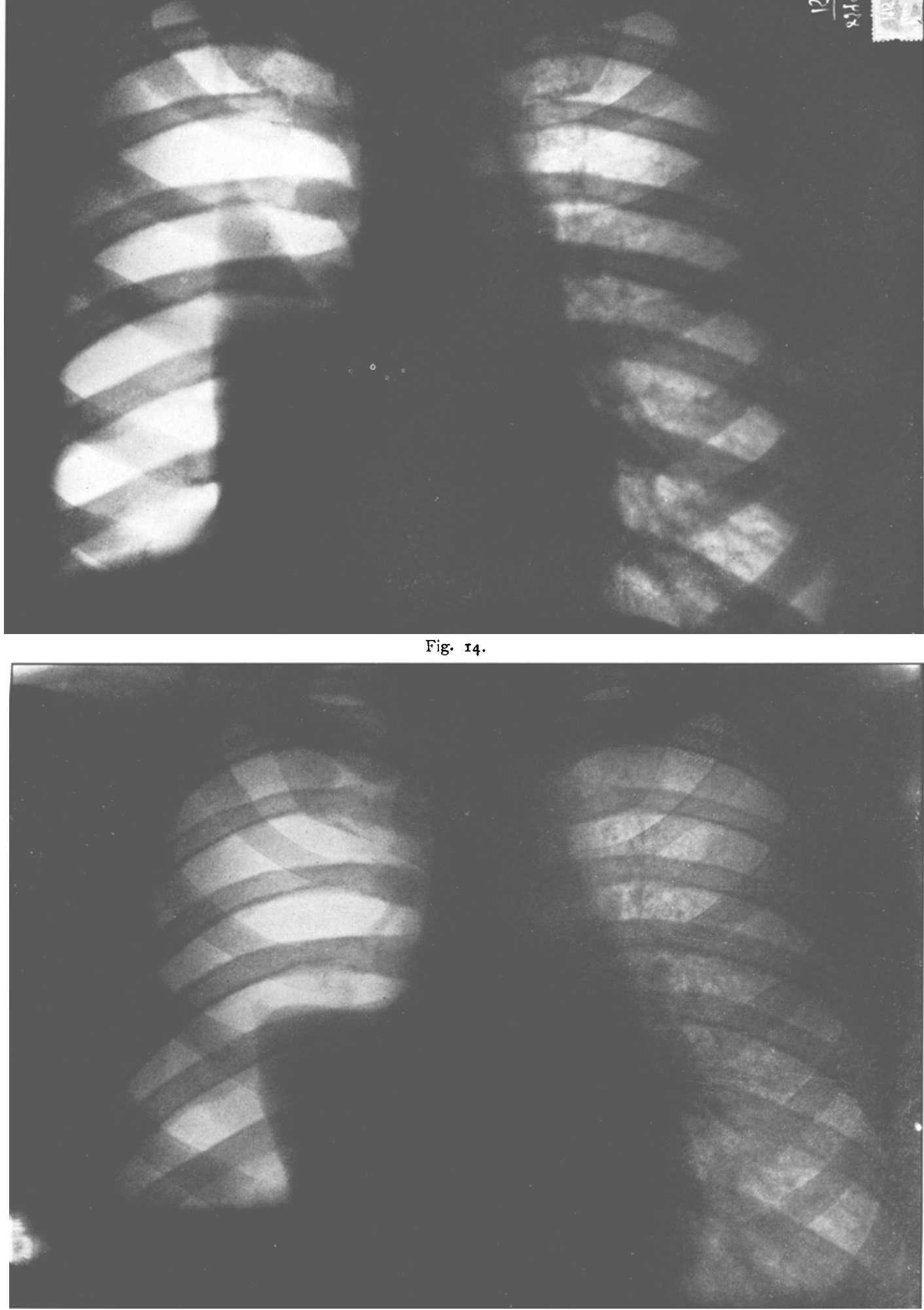

Fig. 15.

Jacobaeus, Endopleurale Operationen unter Leitung des Thorakoskops. 


\section{Beiträge aur Klinik der Tuberkulose. Bd. XXXV.}

Tafel IX.

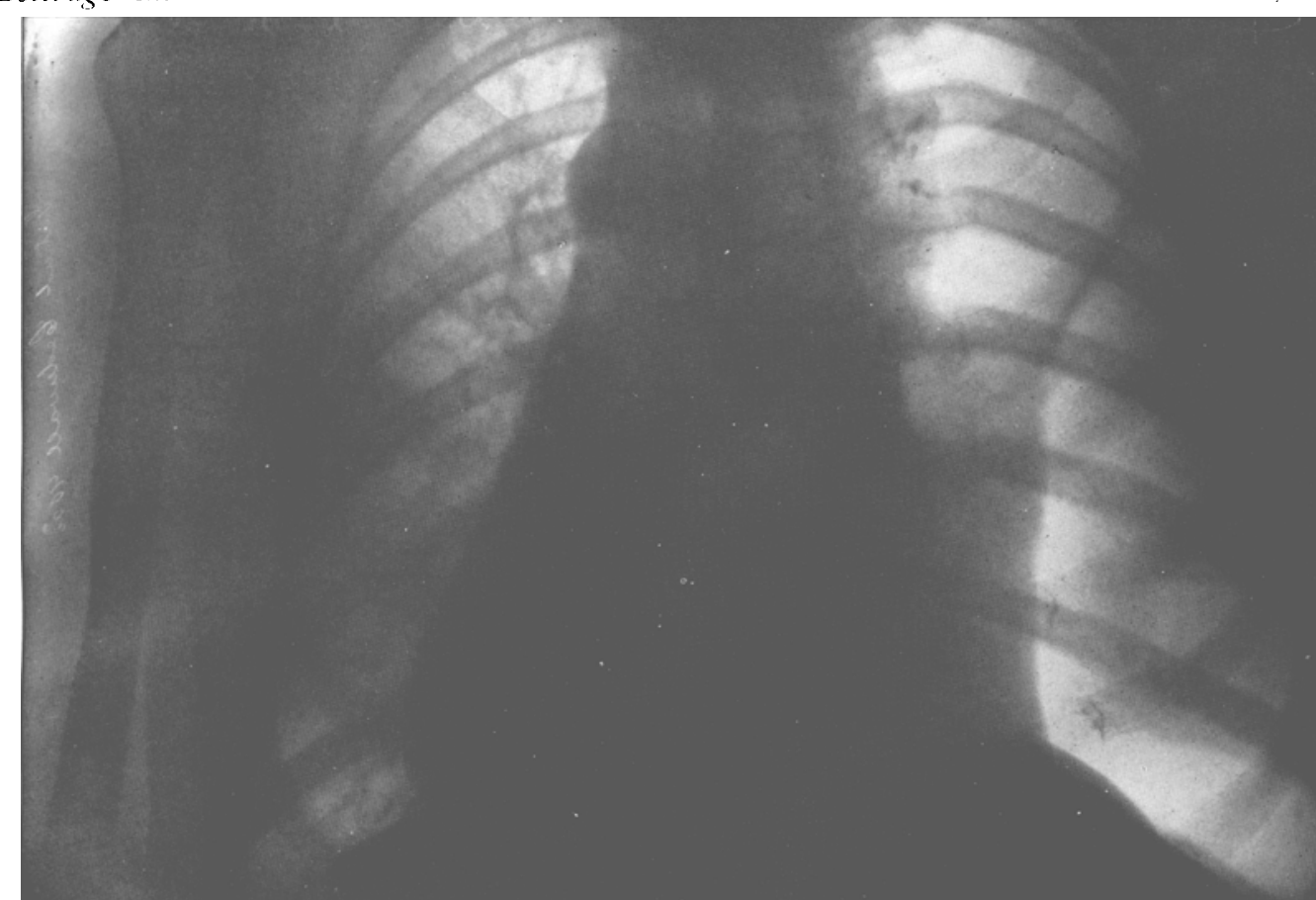

Fig. 16.

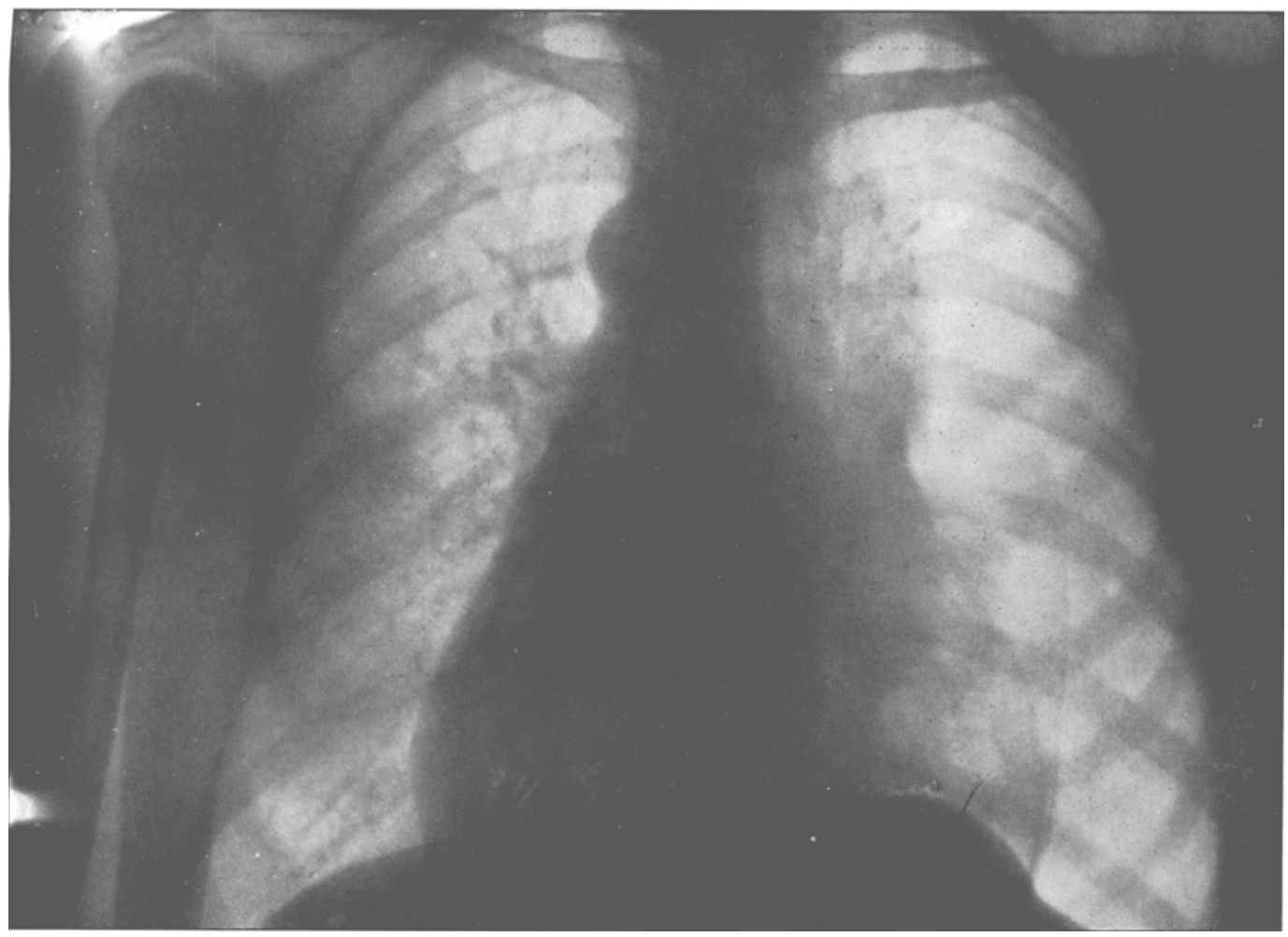

Fig. I 7 .

Jacobaeus, Endopleurale Operationen unter Leitung des Thorakoskops.

Verlag von Curt Kabitzsch, Kgl. Univ.-Verlagsbuchhändler, Würzburg. 